\title{
AMPKa1 deletion in myofibroblasts exacerbates post-myocardial infarction fibrosis by a connexin 43 mechanism
}

\author{
Cécile Dufeys ${ }^{1}$ - Evangelos-Panagiotis Daskalopoulos ${ }^{1} \cdot$ Diego Castanares-Zapatero $^{1} \cdot$ Simon J. Conway ${ }^{2}$. \\ Audrey Ginion ${ }^{1}$. Caroline Bouzin ${ }^{3}$. Jérôme Ambroise ${ }^{4}$. Bertrand Bearzatto ${ }^{4}$. Jean-Luc Gala ${ }^{4}$. Stephane Heymans ${ }^{5}$. \\ Anna-Pia Papageorgiou ${ }^{5,6}$. Stefan Vinckier ${ }^{7}$. Julien Cumps ${ }^{1}$. Jean-Luc Balligand ${ }^{8}$. Maarten Vanhaverbeke ${ }^{6,9}$. \\ Peter Sinnaeve $e^{6,9} \cdot$ Stefan Janssens $^{6,9} \cdot$ Luc Bertrand $^{1} \cdot$ Christophe Beauloye $^{1,10} \cdot$ Sandrine Horman $^{1} \mathbb{D}$
}

Received: 28 May 2020 / Accepted: 8 January 2021 / Published online: 9 February 2021

(c) The Author(s) 2021

\begin{abstract}
We have previously demonstrated that systemic AMP-activated protein kinase $\alpha 1$ (AMPK $\alpha 1$ ) invalidation enhanced adverse LV remodelling by increasing fibroblast proliferation, while myodifferentiation and scar maturation were impaired. We thus hypothesised that fibroblastic AMPK $\alpha 1$ was a key signalling element in regulating fibrosis in the infarcted myocardium and an attractive target for therapeutic intervention. The present study investigates the effects of myofibroblast (MF)-specific deletion of AMPK $\alpha 1$ on left ventricular (LV) adaptation following myocardial infarction (MI), and the underlying molecular mechanisms. MF-restricted AMPK $\alpha 1$ conditional knockout (cKO) mice were subjected to permanent ligation of the left anterior descending coronary artery. cKO hearts exhibit exacerbated post-MI adverse LV remodelling and are characterised by exaggerated fibrotic response, compared to wild-type (WT) hearts. Cardiac fibroblast proliferation and MF content significantly increase in cKO infarcted hearts, coincident with a significant reduction of connexin 43 (Cx43) expression in MFs. Mechanistically, AMPK $\alpha 1$ influences $\mathrm{Cx} 43$ expression by both a transcriptional and a post-transcriptional mechanism involving miR-125b-5p. Collectively, our data demonstrate that MF-AMPK 1 functions as a master regulator of cardiac fibrosis and remodelling and might constitute a novel potential target for pharmacological anti-fibrotic applications.
\end{abstract}

Keywords Cardiac fibrosis · Cardiac fibroblast $\cdot$ Myofibroblast $\cdot$ AMPK $\alpha 1 \cdot$ Connexin $43 \cdot \operatorname{miR}-125 b-5 p$

Cécile Dufeys and Evangelos-Panagiotis Daskalopoulos contributed equally.

Sandrine Horman

sandrine.horman@uclouvain.be

1 Pôle de Recherche Cardiovasculaire (CARD), Institut de Recherche Expérimentale et Clinique (IREC), Université Catholique de Louvain (UCLouvain), 55, Avenue Hippocrate, 1200 Brussels, Belgium

2 HB Wells Center for Pediatric Research, Indiana University School of Medicine, Indianapolis, IN, USA

3 IREC Imaging Platform, Institut de Recherche Expérimentale et Clinique (IREC), Université Catholique de Louvain (UCLouvain), Brussels, Belgium

4 Centre de Technologies Moléculaires Appliquées, Institut de Recherche Expérimentale et Clinique, UCL, Brussels, Belgium
5 Center for Heart Failure Research, Cardiovascular Research Institute Maastricht (CARIM), Maastricht University, Maastricht, The Netherlands

6 Department of Cardiovascular Sciences, KU Leuven, Louvain, Belgium

7 Center for Cancer Biology, University of Leuven and VIB, Louvain, Belgium

8 Pôle de Pharmacologie et de Thérapeutique (FATH), Institut de Recherche Expérimentale et Clinique (IREC), Université Catholique de Louvain (UCLouvain), Brussels, Belgium

9 Department of Cardiovascular Medicine, Leuven University Hospitals, Louvain, Belgium

10 Division of Cardiology, Cliniques Universitaires Saint-Luc, Brussels, Belgium 


\section{Introduction}

Myocardial infarction (MI) is a major cause of mortality and morbidity worldwide, in spite of improved prevention and therapy [23, 24]. The acute loss of cardiomyocytes is followed by adverse cardiac remodelling because of excessive volume and pressure load on non-infarcted areas. This process encompasses the development of cardiomyocyte hypertrophy, myocardial fibrosis, dilatation, and electrophysiological changes, all leading to left ventricular (LV) dysfunction, and eventually, heart failure and death [18, 24]. Fibrosis holds a prominent role in adverse LV remodelling, and has become a prime focus in cardiac research [17].

Resident cardiac fibroblasts (CFs) are present in the myocardium, playing a key role in regulating extracellular matrix (ECM) turnover [65]. Under stress conditions, as in $\mathrm{MI}, \mathrm{CFs}$ become activated and respond to changes in their microenvironment by acquiring a wide range of phenotypic profiles $[19,26]$. They notably differentiate into myofibroblasts (MFs), with enhanced ECM synthesis and smooth muscle-like contractile properties [19]. Whereas MFs can arise from a variety of cell types, most originate from resident CFs $[31,46]$. MFs express $\alpha$-smooth muscle actin $(\alpha \mathrm{SMA})$ and orchestrate the deposition of collagen and secretion of a wide range of structural and non-structural ECM proteins leading to the formation of a stable scar [19]. As the scar matures, the MFs cease to express $\alpha$ SMA and achieve a new differentiated state (matrifibrocyte), which is characterised by high expression of cartilage and tendon genes $[19,26]$. Although the fibrotic response proves essential to scar formation and survival in the early post-MI stages, it eventually leads to deleterious adverse LV remodelling in the longer term, both in the infarcted and the remote myocardium [17].

Fibrosis is amenable to numerous regulatory mechanisms, notably by Transforming growth factor (TGF)- $\beta$ signalling [33]. Among less frequently studied pathways, connexins (Cxs) can likewise trigger fibrosis [15, 16, 29]. $\mathrm{Cxs}$ are membrane proteins that assemble into hexamers and form hemichannels or gap junction channels with essential roles in the communication with the extracellular space or between adjacent cells. Several Cxs exist, of which $\mathrm{Cx} 43$ is the most abundantly expressed isoform in cardiac ventricles [44]. Cx43 is not only a key element in propagating the action potential (myocyte-myocyte communication), but it also facilitates the communication between myocytes and CFs [41, 58]. Interestingly, in the atrial fibrillation disease process, atrial gap junction interruption, due to $\mathrm{Cx} 43$ downregulation, is associated with enhanced fibrosis, which contributes further to the slowing of conduction and formation of reentry [48].
This characteristic structural and electrical remodelling in atria can be recapitulated in cardiac-specific liver kinase B1 (LKB1) knockout (KO) mice, a model that accurately reproduces human atrial fibrillation [52]. LKB1 encodes a serine/threonine protein kinase which functions upstream of the AMP-activated protein kinase (AMPK) superfamily. Several recent studies support the link between AMPK signalling and $\mathrm{Cx} 43$ expression, not only in cardiomyocytes [1,40] but also in CFs [7], proposing a role for this pathway in the fibrotic response commonly seen with a variety of cardiac pathologies.

AMPK, a highly conserved enzyme, is omnipresent in all eukaryotes. The AMPK subunits $(\alpha, \beta$, and $\gamma)$ demonstrate tissue-specific expression with AMPK $\alpha 2$ being the most commonly expressed $\alpha$ subunit in murine cardiomyocytes. Our group, as well as others, have demonstrated its critical protective role in post-ischaemic and failing hearts [11], against excessive cardiac hypertrophy [20, 73, 74], and arrhythmias [4]. On the other hand, AMPK $\alpha 1$ is principally expressed in non-myocyte cardiac cells, including CFs [49], endothelial cells [5], smooth muscle cells [25], platelets [38, 50], and mesenchymal stem cells [12]. We have previously reported on cardiac AMPK $\alpha 1$ as a crucial player in regulating the $\mathrm{CFs} / \mathrm{MFs}$ ratio following ischaemia, thereby demonstrating its cardinal significance in limiting LV remodelling post-MI [49]. However, the exact contribution of MF-AMPK $\alpha 1$ towards this cardioprotective effect is still unclear.

In the current study, we have achieved MF-specific AMPK $\alpha 1$ deletion using Cre-recombinase driven by the periostin (Postn) promoter in AMPK $\alpha 1^{\mathrm{f} / \mathrm{fl}}$ mice. We report that MF-specific knockout (cKO) of AMPK $\alpha 1$ was associated with enhanced fibrosis, as well as adverse cardiac remodelling following MI. Our data shed light onto the intricate roles of myofibroblastic AMPK $\alpha 1$, underscoring the role of $\mathrm{Cx} 43$ as a novel target involved in adverse LV remodelling post-MI.

\section{Methods}

A detailed description of reagents and methods is also presented in the Electronic Supplementary Material.

\section{Animal care}

Animal handling and experimental procedures were approved by the local authorities (Comité d'éthique facultaire pour l'expérimentation animale, 2012/UCL/MD/003 and 2016/UCL/MD/027) and performed in accordance with the Guide for the Care and Use of Laboratory Animals, published by the US National Institutes of Health (NIH Publication, revised 2011). All animals were housed with a 
12-h/12-h light/dark cycle, with the dark cycle occurring from 6.00 p.m. to 6.00 a.m. Mice were observed daily with free access to water and standard chow.

\section{Experimental animals}

We generated an injury-inducible MF-specific KO mouse model in which AMPK $\alpha 1$ could be specifically deleted in MFs in response to cardiac injury. In this model, the Crerecombinase is driven by a 3.9-kb partial mouse Postn promoter (kindly provided by Simon J. Conway, Indiana University) $[35,37,60,64]$. Postn-Cre ${ }^{+/-}$mice were bred with AMPK $\alpha 1^{\mathrm{f} / \mathrm{fl}}$ mice that possess loxP sites flanking exon 3 of PRKAA1 gene (commercially available, Jackson Laboratory, \#014141) to generate MF-specific AMPK $\alpha 1 \mathrm{KO}$ mice (cKO). Postn-Cre ${ }^{-l-} ; A M P K \alpha 1^{\mathrm{f} / / \mathrm{fl}}$ (WT) littermates were used as controls. cKO progeny were viable, fertile and reproduced at expected Mendelian ratios, and showed no overt pathological phenotypes.

To further demonstrate the MF-specific activity of Crerecombinase, we used a reporter mice model. Postn-Cre mice were bred with R26-stop ${ }^{\mathrm{t} / \mathrm{f}}$-enhanced yellow fluorescent protein (EYFP) reporter animals exhibiting the EYFP gene into the Rosa26 locus, preceded by a loxP-flanked stop sequence (kindly provided by Patrick Gilon, UCLouvain) [63].

\section{Mouse model of myocardial infarction}

MI was induced in 10- to 12-week-old male and female mice by left anterior descending (LAD) coronary artery permanent ligation performed by an experienced operator. Animals were pre-treated with buprenorphine hydrochloride $(0.1 \mathrm{mg} /$ Kg, i.p.), anesthetised with 2,2,2-tribromoethanol/2-methyl2-butanol (310 $\mathrm{mg} / \mathrm{Kg}$, i.p.), and their tracheas were intubated. After left-sided thoracotomy at the fourth intercostal space, the LAD coronary artery was ligated below its origin using 8.0 polyamide silk $1-2 \mathrm{~mm}$. Infarction was confirmed by visualisation of ventricle cyanosis under the microscope. The heart was subsequently replaced into the thoracic cavity, and the chest closed. Sham animals underwent a similar surgical procedure, except for the coronary ligation. Animals were euthanized with pentobarbital sodium $(90 \mathrm{mg} / \mathrm{Kg}$, i.p. $)$ on days $3,7,14$, or 3 months post-surgery. Mice were randomly assigned to sham or MI. All investigators conducting the experiments, acquiring and analysing the data were blinded to the experimental groups.

\section{Echocardiography}

Transthoracic echocardiography was performed on anesthetised mice (3-4\% of isoflurane for induction and 1-2\% for maintenance, in $100 \%$ oxygen) using a Vevo 2100
Imaging System (FUJIFILM VisualSonics, Toronto, Canada) equipped with a $30 \mathrm{MHz}$ transducer. Cardiac parameters were measured in 2-dimensional (2D) B-mode long axis and M-mode. Infarct extent was determined by analysing regional LV wall motion 2 days post-MI, based on adjustments for human heart imaging [6]. Echocardiography was performed at baseline (1-3 days pre-op), 1, 7 and 14 days, and 1, 2, and 3 months post-MI. LV volumes were measured using B-mode parasternal long-axis view, at end-systole and end-diastole, from which ejection fraction (EF \%) was deduced. LV mass was calculated from LV long-axis measurements and normalised by tibia length. Fractional shortening (FS \%) was calculated using internal LV dimensions and wall thickness (septum and posterior wall) measurements at end-systole and end-diastole obtained from M-mode recordings. All measurements and analysis were performed by the same experienced operator who was blinded to the experimental groups.

\section{Picrosirius red staining and polarised light microscopy}

Heart sections were treated with $1 \%$ phosphomolybdic acid for 2 min, washed with $\mathrm{H}_{2} \mathrm{O}$ and incubated in $0.1 \%$ picrosirius red solution for $2 \mathrm{~h}$ at room temperature. Sections were then quickly rinsed in hydrochloric acid $0.01 \mathrm{M}$, washed with $\mathrm{H}_{2} \mathrm{O}$, and mounted with Entellan. Stainings were digitised using the Leica SCN400 slide scanner (Leica Microsystems). Myocardial fibrosis was analysed on four to seven heart sections per animal using TissueIA software (Leica Biosystems). Fibrosis was quantified as picrosirius red positive area relative to total area of interest. Scar circumference was assessed by measuring the largest circumference of serial sections from apex to base. Collagen fibres quality was investigated by analysing picrosirius red staining using Axioskop 40 microscope (Carl Zeiss) with a polarising filter. The amount of thick, closely packed, red-orange collagen fibres was compared with that of thin, loosely assembled, green-yellow fibres. Analysis was conducted using FRIDA software (Framework for Image Dataset Analysis, The Johns Hopkins University, USA).

\section{Fluorescent immunohistochemistry}

After endogenous peroxidases inhibition with $3 \% \mathrm{H}_{2} \mathrm{O}_{2}$ for $20 \mathrm{~min}$ and antigen retrieval by microwave heating for 15 min in citrate buffer $\mathrm{pH} 6$, heart sections were permeabilized in Tris-Buffered Saline (TBS) $/ 0.1 \%$ Tween 20 and blocked for 30 min with 5\% BSA solution. EYFP expression, $\mathrm{CF}$ myodifferentiation and proliferation were assessed by double staining with GFP $(1: 2000) \alpha$ SMA (1:5000) or PCNA (1:800), respectively, as well as vimentin $(1: 10,000)$ antibodies. Primary antibodies were 
incubated for $90 \mathrm{~min}$ at room temperature, with slides washed with TBS/0.1\% Tween 20. Slides were then incubated for 40 min with horseradish peroxidase (HRP)-conjugated polymer secondary antibody at room temperature, washed, and incubated with either Alexa Fluor 488 or 555 tyramide reagent (1:200) for $10 \mathrm{~min}$. After washing, nuclei were stained with Hoechst 33,342 $(10 \mu \mathrm{g} / \mathrm{mL})$, and slides were mounted. Omission of the primary antibody served as negative control. Pictures were acquired using an Axio Imager.z1 microscope (Carl Zeiss) with a $20 \times$ objective. EYFP expression, myodifferentiation and proliferation were analysed along the entire infarcted LV wall, remote and border areas, on 4 randomly selected heart sections per animal (10-20 images per animal), using Axiovision software (Carl Zeiss).

\section{Electron microscopy}

Hearts were rinsed using retrograde perfusion with $0.9 \%$ $\mathrm{NaCl}$, followed by perfusion with Karnovsky fixative. The heart was separated into infarct area, border zone, and remote area, and cut into $1 \mathrm{~mm}^{3}$ pieces. Following overnight incubation in Karnovsky fixative, heart pieces were washed and transferred to a $1 \%$ osmium tetroxide postfixative solution buffered with sodium cacodylate buffer. Prior to embedding in Epon, the material was dehydrated in a graded ethanol series. Semi-thin $( \pm 1 \mathrm{~mm})$ sections were cut with a Reichert Jung Ultracut $\mathrm{E}$ microtome and stained with $0.1 \%$ thionin- $0.1 \%$ methylene blue. The ultra-thin $( \pm 70 \mathrm{~nm})$ sections, on copper grids, were stained with uranyl acetate and lead citrate. Transmission electron microscopy was performed on a JEOL JEM1400 (JEOL Europe BV) (VIB Bio Imaging Core, Leuven Platform). Both collagen fibre density and diameter were determined using Image J software (version 1.6, National Institutes of Health, Bethesda, USA).

\section{Isolation of adult murine non-myocyte cells from cardiac muscle tissue}

LVs were excised, rinsed in cold PBS, minced in small pieces, and digested using $100 \mathrm{U} / \mathrm{mL}$ Type II collagenase for $15 \mathrm{~min}$ at $37{ }^{\circ} \mathrm{C}$. The collagenase medium containing the cardiac cell suspension was centrifuged 5 min at $1000 \mathrm{~g}$, and cells were resuspended in Dulbecco's modified eagle medium (DMEM) using 10\% FBS and 2\% penicillin/streptomycin. The digestion step was repeated until all heart pieces were digested (around 6-7 times). Cells were plated and allowed to attach for $1 \mathrm{~h}$, following which the medium was changed to remove poorly adherent cells including cardiomyocytes, endothelial cells, and blood cells.

\section{Primary human cardiac fibroblast culture and treatments}

Human CFs (HCFs) were purchased from ScienCell Research Laboratories (\#6300). Cells are isolated from human healthy heart, cryopreserved at passage one and delivered frozen. Each vial contains $>5 \times 10^{5}$ cells in $1 \mathrm{~mL}$ volume. They are characterised by immunofluorescence with an antibody specific to fibronectin. HCF are negative for HIV-1, HBV, HCV, mycoplasma, bacteria, yeast, and fungi and guaranteed to further expand for 15 population doublings under the conditions provided by ScienCell Research Laboratories. Cells were cultured according to the manufacturer's recommendations. They were transfected with $30 \mathrm{nM}$ AMPK $\alpha 1$ - or $15 \mathrm{nM} \mathrm{Cx} 43$-targeting siRNA constructs or control siRNA (si-scramble) construct using Lipofectamine RNAiMAX transfection reagent for $48 \mathrm{~h}$ following the manufacturer's instructions.

\section{Cell proliferation assay}

Transfected HCFs were serum starved for $24 \mathrm{~h}$ prior to stimulation with 1\% FBS for $48 \mathrm{~h}$. Gap19 $100 \mu \mathrm{M}$ was added at the time of proliferation stimulation. Proliferation was measured by flow cytometry (BD FACS Calibur, Becton Dickinson) with Click-iT Edu flow cytometry assay kit according to the manufacturer's recommendations. The data were analysed by FLOWJO software (version 8.8.7, Tree Star and Leland Stanford Junior University).

\section{Overexpression or knockdown of miR-125b-5p}

HCFs were transfected with $40 \mathrm{nM}$ miR-125b-5p mimic (or si-scramble as negative control) for $48 \mathrm{~h}$ using Lipofectamine RNAiMAX transfection reagent, following the manufacturer's instructions. For the endogenous miR125b-5p knockdown experiment, HCFs were transfected with $30 \mathrm{nM}$ AMPK $\alpha 1$-targeting siRNA or a scramble siRNA for $6 \mathrm{~h}$, as previously described. The medium was then replaced, and HCFs were transfected with $50 \mathrm{nM}$ antagomir125b-5p or antagomir control for $42 \mathrm{~h}$, using Lipofectamine RNAiMAX transfection reagent.

\section{mRNA and microRNA extraction and expression analysis}

Total RNA was isolated from HCFs, isolated mouse CFs or mouse LV with RNeasy mini-kit and miRNeasy minikit, for mRNA and microRNA analyses, respectively, and samples were treated with DNase according to the manufacturer's instructions. RNA was quantified using NanoDrop (Thermo Fisher Scientific), $1 \mu \mathrm{g}$ was reverse transcribed, and real-time quantitative PCR (RT-qPCR) using 
SYBR Green was employed for mRNA and microRNA expression analyses. Reactions were performed on an IQ5 apparatus (Bio-Rad). RPL32 was applied as housekeeping gene for mRNA measurement, and SNORD96A for microRNAs.

\section{RNA sequencing}

Total RNA was isolated from HCFs and treated with DNase as described above. RNA was quantified using Qubit 4 Fluorometer (Thermo Fisher Scientific). RNA integrity was evaluated on the Agilent 2100 Bioanalyzer. All samples had RNA integrity number values $\geq 9.9$. Libraries were prepared starting from $150 \mathrm{ng}$ of total RNA using the KAPA RNA HyperPrep Kit with RiboErase following the manufacturer's recommendations. Libraries were equimolarly pooled and sequenced on a single lane on an Illumina NovaSeq 6000 platform. All libraries were paired-end sequenced and a minimum of 25 million of paired-end reads were generated per sample. All sequencing data were analysed using the Automated Reproducible MOdular workflow for preprocessing and differential analysis of RNA-seq data (ARMOR) pipeline [51]. In this pipeline, reads underwent a quality check using FastQC (Babraham Bioinformatics). Quantification and quality control results were summarised in a MultiQC report [14] before being mapped using Salmon [53] to the transcriptome index which was built using all Ensembl cDNA sequences obtained in the Homo_sapiens.GRCh38.cdna.all.fa file. Then, estimated transcript abundances from Salmon were imported into R using the tximeta package [61] and analysed for differential gene expression with edgeR [56]. Raw and processed RNA-seq data were deposited and made publicly available on the Gene Expression Omnibus (GSE147470).

\section{Statistical analysis}

Data are expressed as means \pm SEM. Normal distribution of continuous variables was tested according to the Shapiro-Wilk method and equality of variances. Statistical significance was evaluated using unpaired student $t$ test for comparing two groups, when they had passed the normality test. The non-parametric Mann-Whitney test was applied for comparing two groups having failed the normality test. Either one-way or two-way ANOVA were employed for multiple comparisons. Post hoc pairwise comparisons were carried out using the Sidak method. Survival analysis was conducted by means of the logrank test. Correlations were analysed using the Pearson coefficient $r$ calculation. Data were analysed using GraphPad prism 8 statistical software.

\section{Results}

\section{Generation and characterisation of MF-specific AMPKa1 KO mice}

To evaluate MF AMPK $\alpha 1$ 's role in regulating MIinduced fibrotic remodelling, we generated mice in which AMPK $\alpha 1$ gene function was specifically deleted in MFs. In this model, Cre-recombinase is driven by a partial mouse Postn promoter [35, 37, 60, 64]. While Postn expression is negligible in the healthy adult heart, it significantly and specifically increases in MFs in the first few days following injury [31]. Importantly for our study, Postn expression is only induced in MF lineage following cardiac insult, and is not present in either resident CFs or myocytes [31, 64]. To generate injury-inducible MF-specific AMPK $\alpha 1 \mathrm{KO}$ mice $(\mathrm{cKO})$, AMPK $\alpha 1^{\mathrm{fl} / \mathrm{fl}}$ mice were bred with Postn-Cre ${ }^{+/-}$mice. Postn-Cre ${ }^{-/-} ; \mathrm{AMPK} 1^{\mathrm{f} / \mathrm{fl}}(\mathrm{WT})$ littermates were employed as controls. To investigate the Cre-mediated AMPK $\alpha 1$ deletion's extent and specificity, we removed the left ventricle from these mice at 14 days post-surgery, and isolated interstitial non-myocyte cells and cardiomyocytes for culture. Non-myocyte cells isolated from sham-operated hearts generally did not express $\alpha$ SMA (Suppl. Figure 1a). Nonetheless, non-myocyte cells isolated from infarcted hearts all became $\alpha$ SMA-positive, displaying characteristic stress fibres of MFs (Suppl. Figure 1b). AMPK $\alpha 1$ expression levels were comparable in CFs isolated from sham-operated mice of both genotypes (Fig. 1a). After MI, AMPK $\alpha 1$ levels dramatically decreased in cKO, in comparison to WT MFs (Fig. 1b), while remaining unchanged in cardiomyocytes (Fig. 1c). AMPK $\alpha 2$ expression did not differ after sham or MI surgery, either in CFs/MFs (Fig. 1d, e, respectively) or cardiomyocytes (Fig. 1f) isolated from WT and cKO hearts. To further demonstrate the non-myocyte specific activity of Cre-recombinase in our animal model, Postn-Cre mice were bred with R26-stop ${ }^{\text {fl/fi }}$-EYFP reporter animals exhibiting the enhanced yellow fluorescent protein (EYFP) gene into the Rosa26 locus, preceded by a loxP-flanked stop sequence [63]. At the histological level, sham-operated Postn-Cre ${ }^{+-} ; \mathrm{R} 26-$ stop $^{\mathrm{f} / \mathrm{fl}}$-EYFP mice displayed very low or no EYFP + interstitial cell levels in the heart (Fig. 1g); whereas 7 days post-MI injury, these mice had abundant EYFP staining, colocalizing with vimentin in the nonmyocyte cells within the infarcted area (Fig. 1h). EYFP expression was low or undetectable in MI-operated Postn$\mathrm{Cre}^{-/-} ; \mathrm{R} 26-$ stop $^{\mathrm{f} / \mathrm{fl}}$-EYFP hearts (Fig. 1i). 
a Isolated CFs - Sham

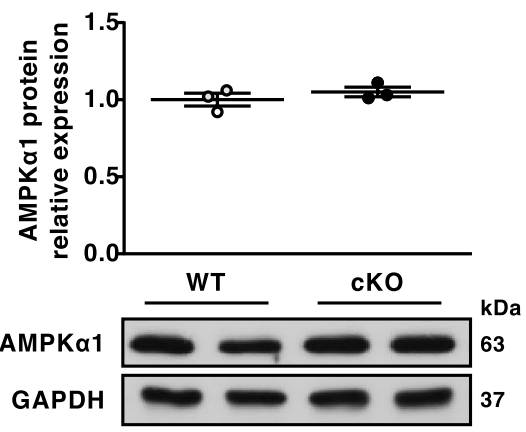

d

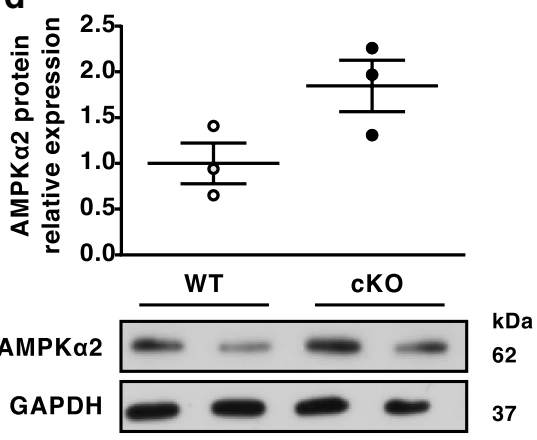

b Isolated MFs - MI

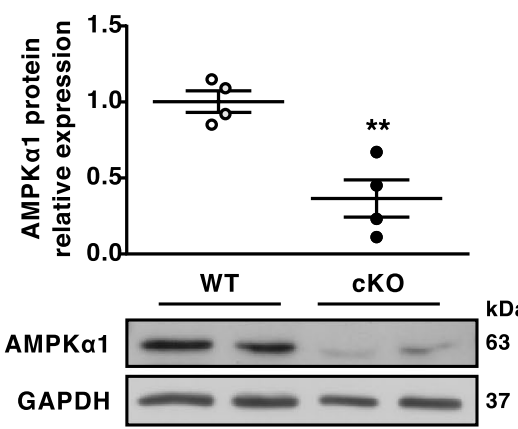

e

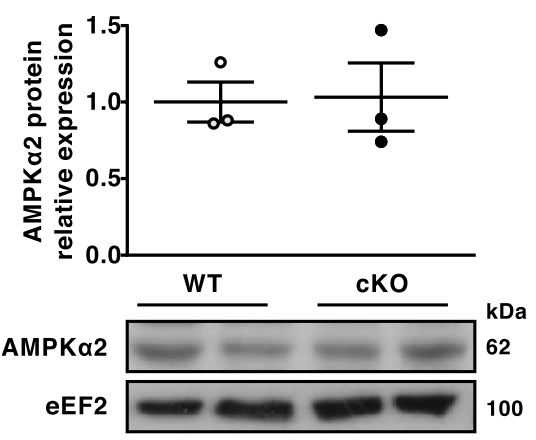

C Isolated CMs - MI

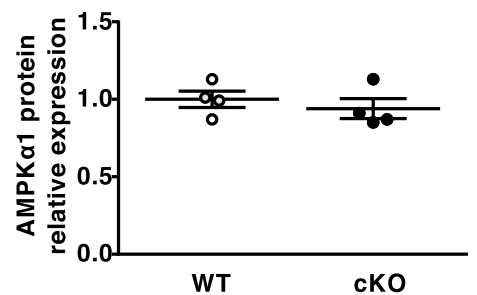

f

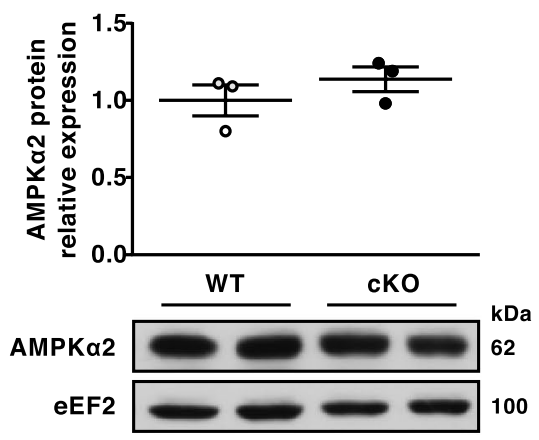

EYFP

Vimentin

Nucleus
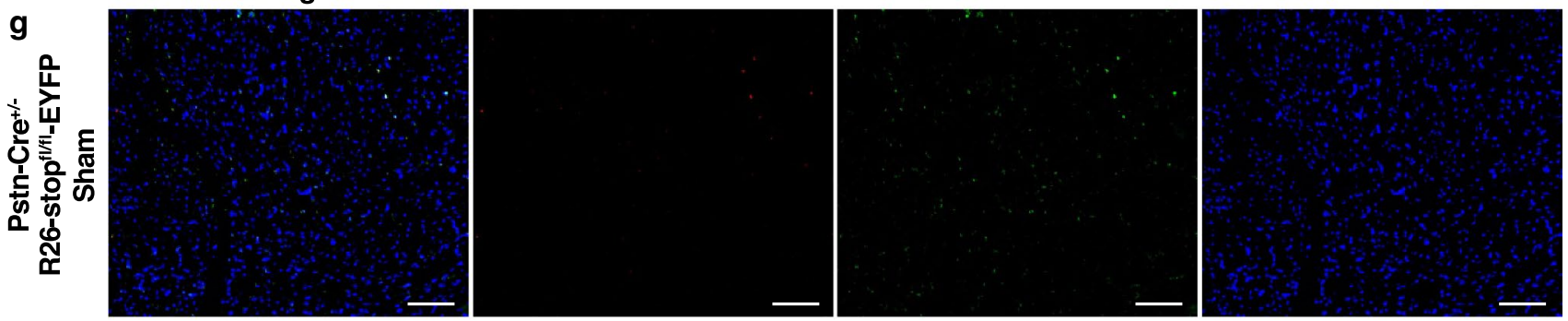

h

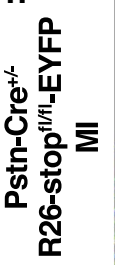
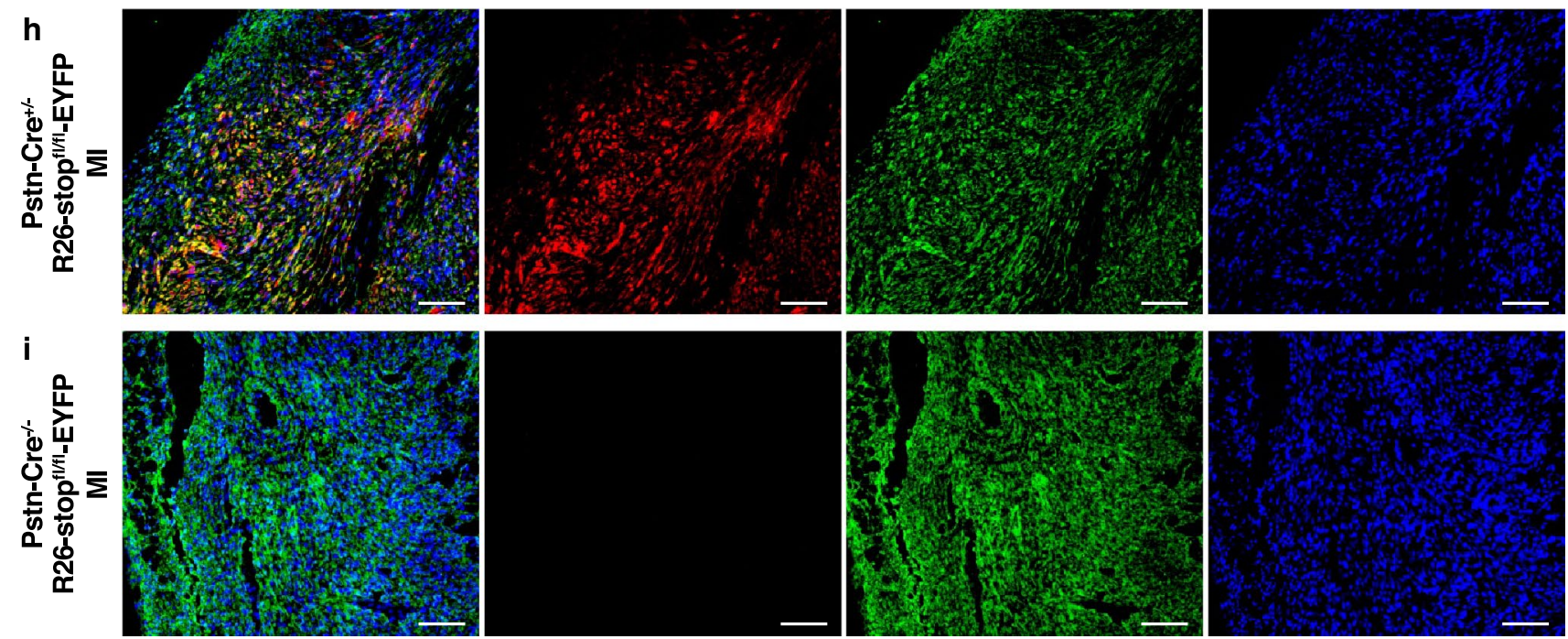
४Fig. 1 Generation and characterisation of MF-specific AMPK $\alpha 1 \mathrm{KO}$ mice. a-f Cardiac fibroblasts (CFs) (a, d), myofibroblasts (MFs) (b, e) and cardiomyocytes (CMs) (c, f) were isolated from MF-specific AMPK $\alpha 1 \mathrm{KO}$ (cKO) and littermates WT (WT) mouse hearts 14 days after sham (a, d) or myocardial infarction (MI) (b, c, e, f) surgery. Western blotting was performed for analysing AMPK $\alpha 1(\mathbf{a}-\mathbf{c})$ or AMPK $\alpha 2$ (d-f) expression ( $n=3-4$ mice/group). Dot plots represent data from individual mouse hearts, as well as mean \pm SEM. Statistical significance was determined by unpaired $t$ test. $* * p<0.01$ compared to WT. g-i Postn-Cre ${ }^{+/-} ;$Rosa26-STOP ${ }^{\mathrm{f} / \mathrm{fl}}$-enhanced yellow fluorescent protein (EYFP) $(\mathbf{g}, \mathbf{h})$ and Postn-Cre ${ }^{-/-} ;$Rosa26-STOP ${ }^{\text {fl/fl }}-\mathrm{EYFP}$ (i) mouse hearts were collected 7 days following $\mathrm{MI}$ (h, i) or sham surgery (g), with EYFP expression assessed by immunohistofluorescence. Representative images of EYFP staining. Magnification: $\times 10$. Scale bars: $100 \mu \mathrm{m}$

\section{MF-specific AMPKa1 deficiency aggravates LV adverse remodelling post-MI}

To investigate MF AMPK $\alpha 1$ 's role in regulating LV remodelling, we first analysed the infarct magnitude by echocardiographic assessment of regional LV wall motion of each operated mouse at 2 days post-MI [49]. The extent of infarcted myocardium did not differ between cKO and WT mice (WT: $7.56 \pm 0.17$ vs cKO: $7.71 \pm 0.16$ number of akinetic segments, $n=55 / 59)$. At baseline, chamber dimensions and LV function were comparable between the two genotypes (Fig. 2a-c and Table 1). From 1 month until 3 months post-MI, cKO animals exhibited a strong increase in LV end-diastolic (LVEDV) and -systolic (LVESV) volumes in comparison to WT littermates (Fig. 2a, b). It was associated with a significant increase in the LV's internal dimension (both in diastole and systole), while no clear difference was observed in intraventricular septum or posterior wall thickness (Table 1). LV mass normalised to tibia length was similar between WT and cKO, at 3 months post-MI (Table 1). Consistent with these data, histological analyses of cardiomyocyte crosssectional area and blood vessel density in the non-infarcted remote myocardium were not different between $\mathrm{cKO}$ and WT mice (Suppl. Figure 2a-c). Lastly, the early mortality (<7 days) (WT: $54.31 \%$ vs cKO: $47.47 \%, n=116 / 99$ ) and the incidence of cardiac rupture (WT: $12.07 \%$ vs cKO: $19.19 \%, n=116 / 99$ ) were similar between genotypes, while impaired cardiac function in cKO animals was associated with a trend towards decreased long-term survival (Fig. 2d).

\section{MF-specific AMPKa1 deficiency enhances LV fibrosis post-MI}

To investigate MF AMPK $\alpha 1$ 's role in cardiac healing, we performed picrosirius red staining at 14 days following MI or sham surgery and measured substantially increased collagen deposition in the infarct, border, and remote areas of cKO mice, compared to WT (Fig. 3a-d).
Fig. 2 MF-specific AMPK $\alpha 1$ deficiency aggravates LV adverse remodelling post-MI. a-c Left ventricular enddiastolic (LVEDV) (a) and -systolic (LVESV) (b) volumes and ejection fraction (EF) (c) of MF-specific AMPK $\alpha 1 \mathrm{KO}$ (cKO) and littermates WT (WT) mice measured by transthoracic echocardiography at the indicated time points postmyocardial infarction (MI) or sham surgery ( $n=10-11$ mice/ group). Results are expressed as mean \pm SEM. Statistical significance was determined by two-way ANOVA followed by Sidak's multiple comparisons test. ** $p<0.01, * * * p<0.001$ compared to corresponding WT. d Kaplan-Meier survival curves of $\mathrm{cKO}$ and WT mice until 3 months after MI ( $n=25-35$ mice/group). Differences between groups were determined by the log-rank test, $p=0.25$
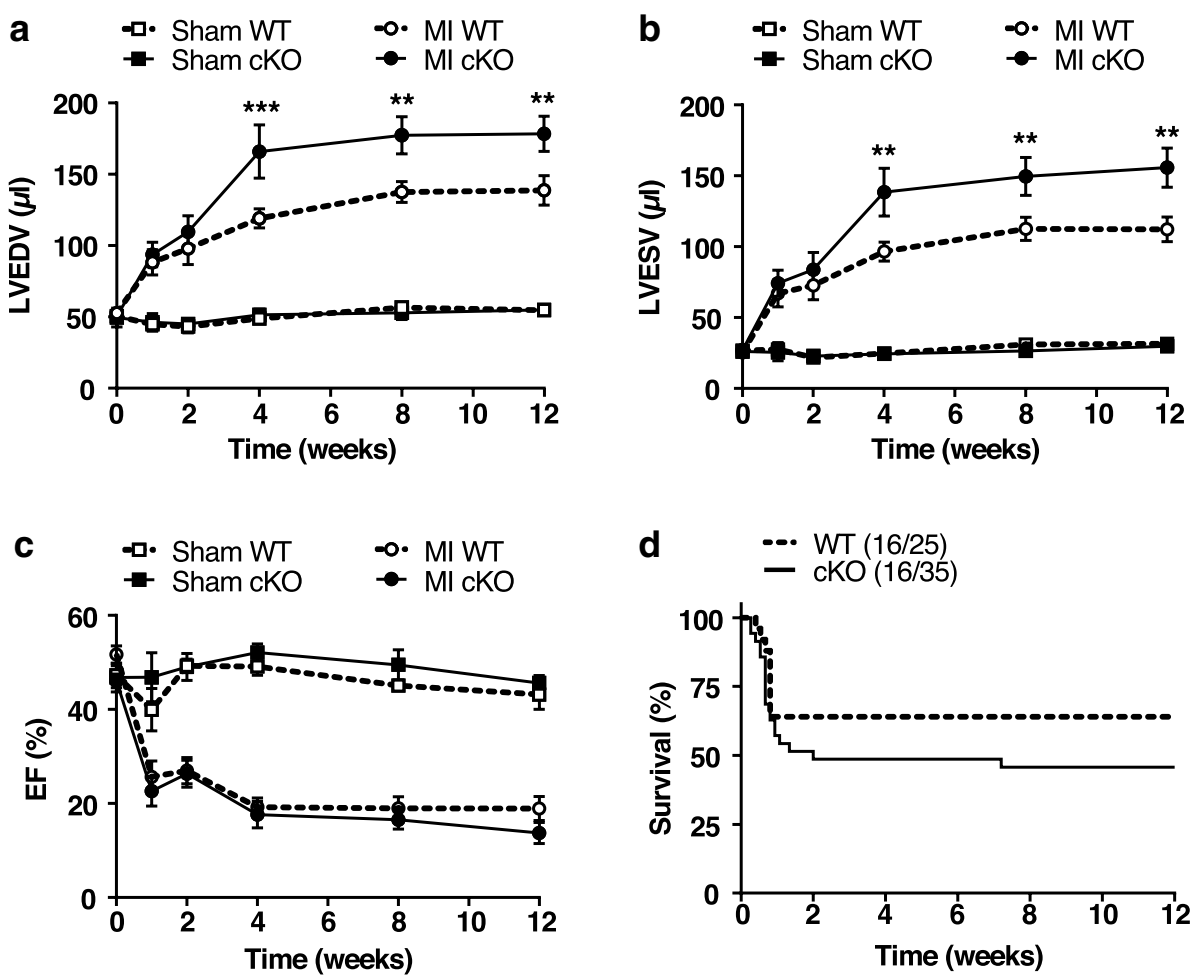
Table 1 Related to Fig. 2 echocardiographic measurements of cKO and WT mice at 3 months after myocardial infarction

\begin{tabular}{|c|c|c|c|c|}
\hline \multirow[t]{2}{*}{ Variable } & \multicolumn{2}{|l|}{ Sham 3 months } & \multicolumn{2}{|l|}{ MI 3 months } \\
\hline & $\mathrm{WT}(n=7)$ & $\mathrm{cKO}(n=5)$ & WT $(n=11)$ & $\mathrm{cKO}(n=10)$ \\
\hline \multicolumn{5}{|l|}{ M-mode } \\
\hline End-diastolic interventricular septal thickness (mm) & $0.59 \pm 0.08$ & $0.56 \pm 0.04$ & $0.70 \pm 0.07$ & $0.59 \pm 0.07$ \\
\hline End-systolic interventricular septal thickness (mm) & $0.85 \pm 0.12$ & $0.78 \pm 0.03$ & $0.88 \pm 0.10$ & $0.77 \pm 0.10$ \\
\hline End-diastolic left ventricular internal diameter (mm) & $3.84 \pm 0.13$ & $4.09 \pm 0.18$ & $5.32 \pm 0.15^{* * *}$ & $5.84 \pm 0.14 * * * \$$ \\
\hline End-systolic left ventricular internal diameter (mm) & $2.80 \pm 0.09$ & $3.09 \pm 0.16$ & $4.63 \pm 0.23$ & $* * * 5.34 \pm 0.22 * * *, \$$ \\
\hline End-diastolic left ventricular posterior wall thickness $(\mathrm{mm})$ & $0.57 \pm 0.07$ & $0.52 \pm 0.01$ & $0.56 \pm 0.05$ & $0.70 \pm 0.06$ \\
\hline End-systolic left ventricular posterior wall thickness (mm) & $0.88 \pm 0.08$ & $0.79 \pm 0.04$ & $0.75 \pm 0.09$ & $0.72 \pm 0.05$ \\
\hline Fractional shortening (\%) & $26.78 \pm 2.07$ & $24.47 \pm 1.46$ & $13.39 \pm 2.07 * * *$ & $8.74 \pm 1.87 * * *$ \\
\hline \multicolumn{5}{|l|}{ 2D parasternal long axis } \\
\hline Left ventricular mass $(\mathrm{mg}) /$ tibial length $(\mathrm{cm})$ & $45.78 \pm 1.95$ & $52.06 \pm 4.37$ & $62.29 \pm 3.67 *$ & $68.00 \pm 5.22 *$ \\
\hline \multicolumn{5}{|l|}{ Pulse Doppler } \\
\hline Heart rate $(\mathrm{bpm})$ & $435.80 \pm 19.04$ & $416.30 \pm 11.69$ & $428.80 \pm 23.39$ & $451.40 \pm 28.18$ \\
\hline
\end{tabular}

Cardiac function parameters of MF-specific AMPK $\alpha 1 \mathrm{KO}(\mathrm{cKO})$ and littermates WT (WT) mice, quantified by transthoracic echocardiography at 3 months after myocardial infarction (MI) or sham surgery $(n=5-11$ mice/group). Data are reported as mean \pm SEM. Statistical significance was determined by two-way ANOVA followed by Sidak's multiple comparisons test

${ }^{*} p<0.05, * * * p<0.001$ compared to corresponding sham and ${ }^{\$} p<0.05$ compared to WT MI.

Picrosirius red polarised light microscopy of cKO scars revealed predominant well-aligned and thickly packed collagen fibres, in contrast to WT infarcts (Fig. 3e). Accordingly, the tightly packed versus loosely packed fibres ratio (red-orange:green-yellow) was significantly higher in infarcts, border zones and remote areas of cKO, compared to WT hearts (Fig. 3f-h). Based on ultrastructural analysis with transmission electron microscopy, cKO infarcts were characterised by a denser and more organised collagen matrix (Fig. 3i-k). Nonetheless, collagen fibres diameter did not differ between both genotypes (Fig. 31), indicating that the cross-linking process was not affected. In support of this, specific AMPK $\alpha 1$ deletion in MFs did not impact lysyl oxidase (LOX) expression in the infarcted myocardium (Suppl. Figure 3a and 3b), despite a trend towards decreased LOX expression in MFs isolated from cKO versus WT hearts (Suppl. Figure 3c). Interestingly, the degree of LV fibrosis was not different between the two genotypes at 3 months following MI, indicating that MF-specific AMPK $\alpha 1$ deficiency merely accelerates fibrotic deposition of collagen in cKO hearts during the early phases of postinfarct healing (Suppl. Figure $4 \mathrm{a}-\mathrm{h}$ ). Importantly, increased fibrosis was not the result of excessive cardiomyocyte mortality in cKO infarcts, as reflected by the measurement of troponin I (TpnI) serum levels at days 1, 2 and 7 post-MI (Fig. $3 \mathrm{~m}$ ). Cardiomyocyte death similarly occurred in the first 2 days in WT and cKO mice, and was barely detected after 7 days (Fig. $3 \mathrm{~m}$ ). Of note, 2 weeks after MI, the number of residual cardiomyocytes in the infarcted myocardium was lower in cKO infarcts (Fig. 3n), possibly as a consequence of increased fibrosis. Altogether, these effects promoted LV dilatation in the longer term, as reflected by the increased scar circumference measured at 3 months (Fig. 30).

Fig. 3 MF-specific AMPK $\alpha 1$ deficiency enhances LV fibrosis postMI a representative images of MF-specific AMPK $\alpha 1 \mathrm{KO}(\mathrm{cKO})$ and littermates WT (WT) infarct areas stained by picrosirius red and visualised under bright-field light. Magnification: $\times 10$. Scale bars: $100 \mu \mathrm{m}$. b-d Quantifications of fibrosis in the infarct (b), border (c) and remote (d) areas of cKO and WT mice ( $n=5-10$ mice/group). Results are expressed as \% of measured tissue area. e Representative images of cKO and WT infarct areas stained by picrosirius red and visualised under polarised light. Magnification: $\times 10$. Scale bars: $100 \mu \mathrm{m}$. f-h Quantification of picrosirius red polarised light analysis in the infarct (f), border (g) and remote (h) areas of cKO and WT mice ( $n=4-5$ mice/group). Results are expressed as red-orange on green-yellow pixel ratio in the measured tissue area. i Representative images of electron microscopy analysis in the infarct area of cKO and WT mice. Scale bars: $500 \mathrm{~nm}$. j-k Quantification of collagen fibres density in the extracellular matrix of infarct (j) and border (k) areas of cKO and WT ( $n=3$ mice/group). Results are expressed as \% of measured tissue area. 1 Proportional distribution of collagen fibrils diameter in the infarct area measured by electron microscopy. m Serum Troponin I (TpnI) measurement at different time points post-MI in cKO and WT mice. Serum were harvested at $24 \mathrm{~h}, 48 \mathrm{~h}$ and 7 days post-MI and TpnI concentration was measured by ELISA ( $n=4-8$ mice/group). $\mathbf{n}$ Histological quantifications of residual cardiomyocytes in the infarct of cKO and WT mice $(n=5-11$ mice/ group). Results are expressed as \% of measured tissue area. o Scar circumference of cKO and WT mice at 3 months post-MI measured from heart sections stained by picrosirius red $(n=6-11$ mice/ group). Scale bars: $1 \mathrm{~mm}$. Hearts were excised at 14 days $(\mathbf{a}-\mathbf{l}, \mathbf{n})$ and 3 months post-MI. Dot plots represent data from individual mice, as well as mean \pm SEM. Statistical significance was determined using unpaired $t$ test $(\mathbf{b}-\mathbf{d}, \mathbf{f}, \mathbf{g}, \mathbf{j}, \mathbf{k})$, Mann-Whitney test $(\mathbf{h}, \mathbf{n}, \mathbf{f})$, or twoway ANOVA followed by Sidak's multiple comparisons test $(\mathbf{l}, \mathbf{m})$.

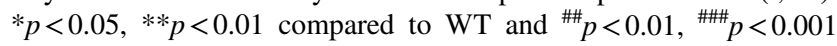
compared to corresponding genotype at 7 days post-MI 

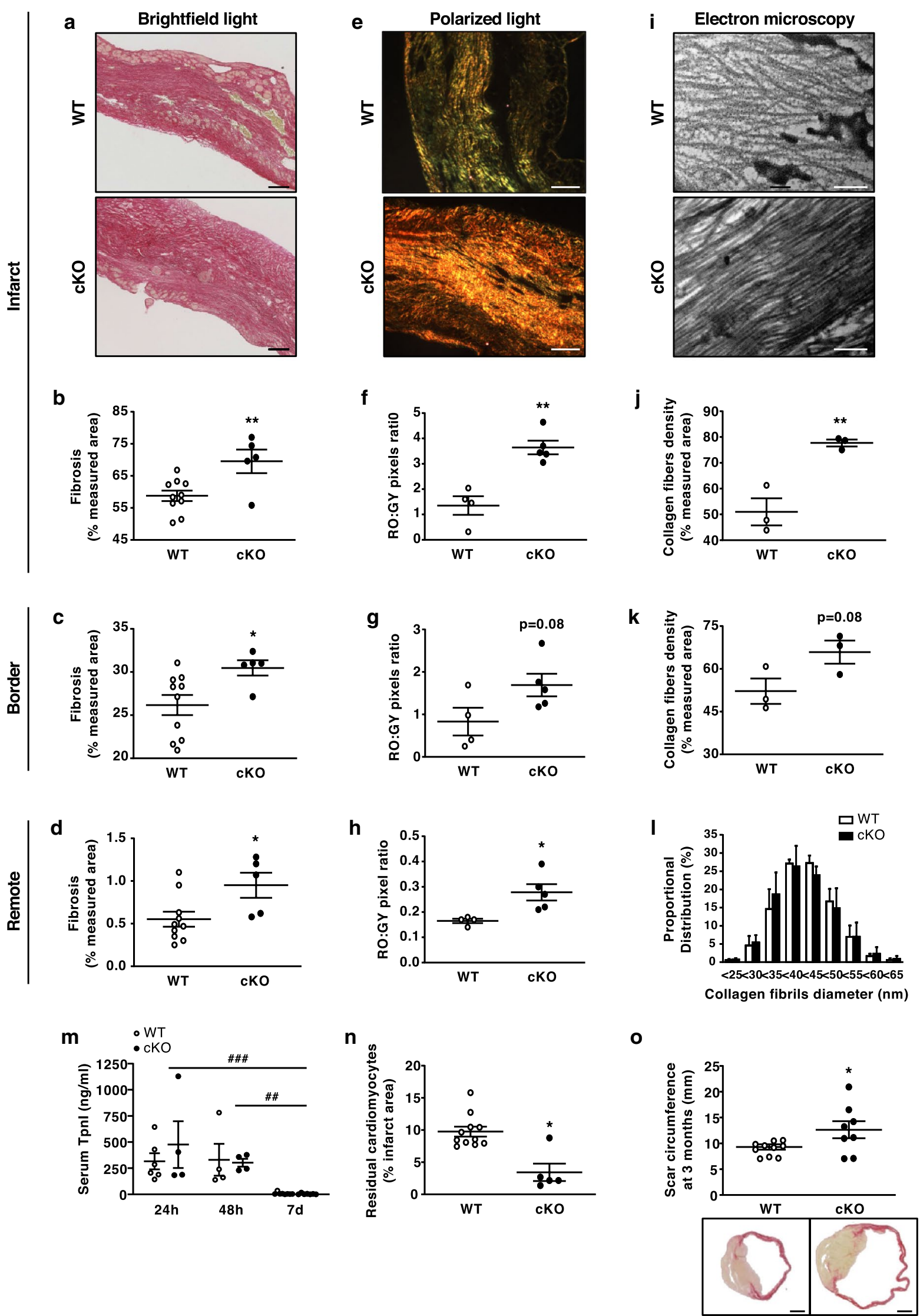


\section{MF-specific AMPKa1 deficiency promotes CF activity}

MF AMPK $\alpha 1$ deletion substantially stimulated the fibrotic response, but underlying cellular mechanisms remain largely unknown. We thus examined CF proliferation using fluorescent immunohistochemistry of proliferating cell nuclear antigen (PCNA) proliferation marker, and vimentin which is commonly used to label interstitial cells and allows to demarcate the infarcted and border areas (Fig. 4a-f). At 7 days post-MI, immunohistochemistry revealed a non-significant trend towards increased proliferation in cKO infarcts, as compared to WT hearts (Fig. 4a, b), while we observed a number of PCNA-positive cells significantly higher in the border zone of cKO (Fig. 4c). Compared to 7 days post-MI, the number of proliferative cells at 14 days after MI was decreased (Fig. 4d-f) but remained significantly higher in both the infarct (Fig. 4e) and border (Fig. 4f) zones of cKO, as compared to WT hearts. The MF staining for $\alpha$ SMA (Suppl Fig. 5a-c) confirmed that, 2 weeks after MI, MFs were significantly more abundant in cKO infarct (Suppl Fig. 5b) and border zones (Suppl Fig. 5c). While it is recognised that fibroblast proliferation declines from days 5 to 7 post-MI to give way to the maturation phase, our results suggest that loss of AMPK $\alpha 1$ gene function in MFs promotes and sustains their proliferation in cKO infarcts, increasing their number, which underlies the enhanced fibrosis in mice with Postn-mediated MF-specific deletion.

\section{AMPKa1 regulates Cx43 expression in CFs}

To identify AMPK $\alpha 1$-dependent gene regulation in fibroblasts, we performed a RNA-sequencing analysis in human CFs (HCFs) transfected with specific small interferingRNA (siRNA) targeting AMPK $\alpha 1$ or control non-targeting siRNA (si-scramble). A total of 7375 genes, representing $53 \%$ of the analysed coding transcriptome, showed a differential regulation between both conditions, supporting the notion that AMPK $\alpha 1$ dramatically influences CF biology (GEO accession number: GSE147470). We selected the 1,846 genes presenting a fold change $\geq 1.5$ and a statistical $p$ value $<0.01$ (Fig. 5a). Among these, we identified several dysregulated genes relevant for fibrosis and/or CF activity regulation including fibrotic factors, collagens and proteases which are demonstrated in the heat map view (Fig. 5b). We also found genes related to cellular proliferation and subsequently focused on CDKN1A (p21), MAPK3 (Erk1) and GJA1 (Cx43) (Fig. 5c-e) for their described interaction with the AMPK $\alpha 1$ signalling [1, 7, 8, 13, 40, 72]. We thus confirmed the RNA-sequencing output for these 3 genes at protein level. Western blot data confirmed that AMPK $\alpha 1$ deficiency decreased p21 and even more drastically Cx43 protein expression (Fig. 5f, g). In contrast, Erk1 expression was not different between both conditions (Fig. 5h). Several studies have linked reduced $\mathrm{Cx} 43$ expression with excessive fibrosis due to increased fibroblastic activity [29, 75, 76]. Accordingly, HCFs transfected with a specific siRNA targeting $\mathrm{Cx} 43$ proliferated faster than fibroblasts transfected with si-scramble (Fig. 5i), while expression of $\alpha$ SMA was not affected in these conditions (Fig. 5j). To further assess the contribution of $\mathrm{Cx} 43$ in the regulation of cardiac fibroblast proliferation, we used the mimetic peptide Gap19, a hemichannel blocker derived from the second cytoplasmic loop of Cx43 [28]. Results show that the HCF proliferation rate is significantly increased by the peptide treatment (Fig. 5k), supporting a central role of $\mathrm{Cx} 43$ hemichannels in the regulation of this process.

\section{AMPKa1 regulates Cx43 transcription and Cx43 mRNA degradation by a mechanism involving miR-125b-5p}

We sought to determine how AMPK $\alpha 1$ could interfere with Cx43 expression. To determine whether reduced expression was regulated at the transcriptional level, HEK293 cells were co-transfected with a $\mathrm{Cx} 43$ promotor-luciferasereporter plasmid and AMPK $\alpha 1$-targeting or scrambled control siRNAs. Similar to HCFs, AMPK $\alpha 1$-deficient HEK293 exhibited decreased Cx43 protein and mRNA levels (Suppl. Figure 6a and 6b). As shown in Fig. 6a, AMPK $\alpha 1$ deletion decreased $\mathrm{Cx} 43$ promotor activity by $\sim 40 \%$ compared to si-scramble, indicating that AMPK $\alpha 1$ regulates $\mathrm{Cx} 43$ transcription. However, this transcriptional regulation alone did not account for the nearly complete loss of $\mathrm{Cx} 43$ protein expression upon AMPK $\alpha 1$ deletion (Fig. $5 \mathrm{~g}$ ), suggesting that post-transcriptional mechanisms may also be involved.

We then explored whether the loss of AMPK $\alpha 1$ gene function affected $\mathrm{Cx} 43$ protein or mRNA stability. We observed no difference between AMPK $\alpha 1$ siRNA and scramble-transfected $\mathrm{HCFs}$ concerning $\mathrm{Cx} 43$ protein degradation by the proteasome (Suppl. Figure 7). To examine Cx43 mRNA stability, we incubated HCFs with actinomycin $\mathrm{D}$ for $9 \mathrm{~h}$ to inhibit RNA polymerase II and de novo transcription, and performed RT-qPCR at different time points to measure $\mathrm{Cx} 43$ mRNA levels. We observed a significant reduction in Cx43 mRNA stability in AMPK $\alpha 1$ siRNAtransfected cells compared with scrambled control siRNAs (Fig. 6b). We hypothesised that Cx43 mRNA downregulation in AMPK $\alpha 1$-deficient cells might be caused by an inhibitory microRNA that targets $\mathrm{Cx} 43$ mRNA. To gain an overview of changes in microRNA expression, a preliminary quantitative PCR microRNA array, containing 83 of the microRNAs common to most cardiovascular diseases, was performed in AMPK $\alpha 1$ siRNA-transfected HCFs. We 
found 43 microRNAs potentially up-regulated in AMPK $\alpha 1$ depleted HCFs (Suppl. Table 1). In silico analysis using the Diana, microRNA.org, and Pictar algorithms identified miR$125 b-5 p$ as having the potential to bind 7 bases of the $\mathrm{Cx} 43$ $3^{\prime} \mathrm{UTR}$ mRNA at a site that is highly conserved across 11 species (Fig. 6c). Using RT-qPCR, we confirmed increased expression of miR-125b-5p in AMPK $\alpha 1$-deficient HCFs (Fig. 6d). To investigate whether miR-125b-5p downregulates $\mathrm{Cx} 43$ protein levels, HCFs were transfected with a miR$125 \mathrm{~b}-5 \mathrm{p}$ mimic or scramble control for $48 \mathrm{~h}$. Cx 43 protein levels were reduced by $50 \%$, as compared to control levels in cells transfected with the miR-125b-5p mimic (Fig. 6e). Very interestingly, reducing miR-125b-5p levels with miR$125 b-5 p$ antagomir counteracted the profound decrease in $\mathrm{Cx} 43$ protein expression as well as the stimulating effect on proliferation induced by AMPK $\alpha 1$ deletion in AMPK $\alpha 1$ deficient cells (Fig. 6f, g). Taken together, these data identify miR-125b-5p as an essential negative regulator of $\mathrm{Cx} 43$, contributing to the significantly reduced $\mathrm{Cx} 43$ expression in AMPK $\alpha 1$-deficient cells.
Fig. 4 MF-specific AMPK $\alpha 1$ deficiency promotes $\mathrm{CF}$ activity. a, $\mathbf{d}$ Representative images of co-immunofluorescent staining of proliferating $\mathrm{CFs}$ (PCNA-positive: red fluorescence, vimentin-positive: green fluorescence) in the infarct area of MF-specific AMPK $\alpha 1$ $\mathrm{KO}(\mathrm{cKO})$ and littermates WT (WT) at 7 (a) and 14 (d) days post-myocardial infarction (MI). b, c Quantification of proliferating $\mathrm{CFs}$ in the infarct (b) or border (c) areas of cKO and WT at 7 days post-MI $(n=9$ mice/ group). e, $\mathbf{f}$ Quantification of proliferating $\mathrm{CFs}$ in the infarct (e) or border (f) areas of cKO and WT at 14 days post-MI ( $n=5-7$ mice/group). Results are expressed as \% of PCNApositive nucleus within the vimentin-stained tissue area. Magnification: $\times 20$. Scale bars: $50 \mu \mathrm{m}$. Dot-plots represent data from individual mice, as well as mean \pm SEM. Statistical significance was determined by unpaired $t$ test $(\mathbf{b}, \mathbf{c}$, f) or Mann-Whitney test (e). $* p<0.05, * * p<0.01$ compared to WT
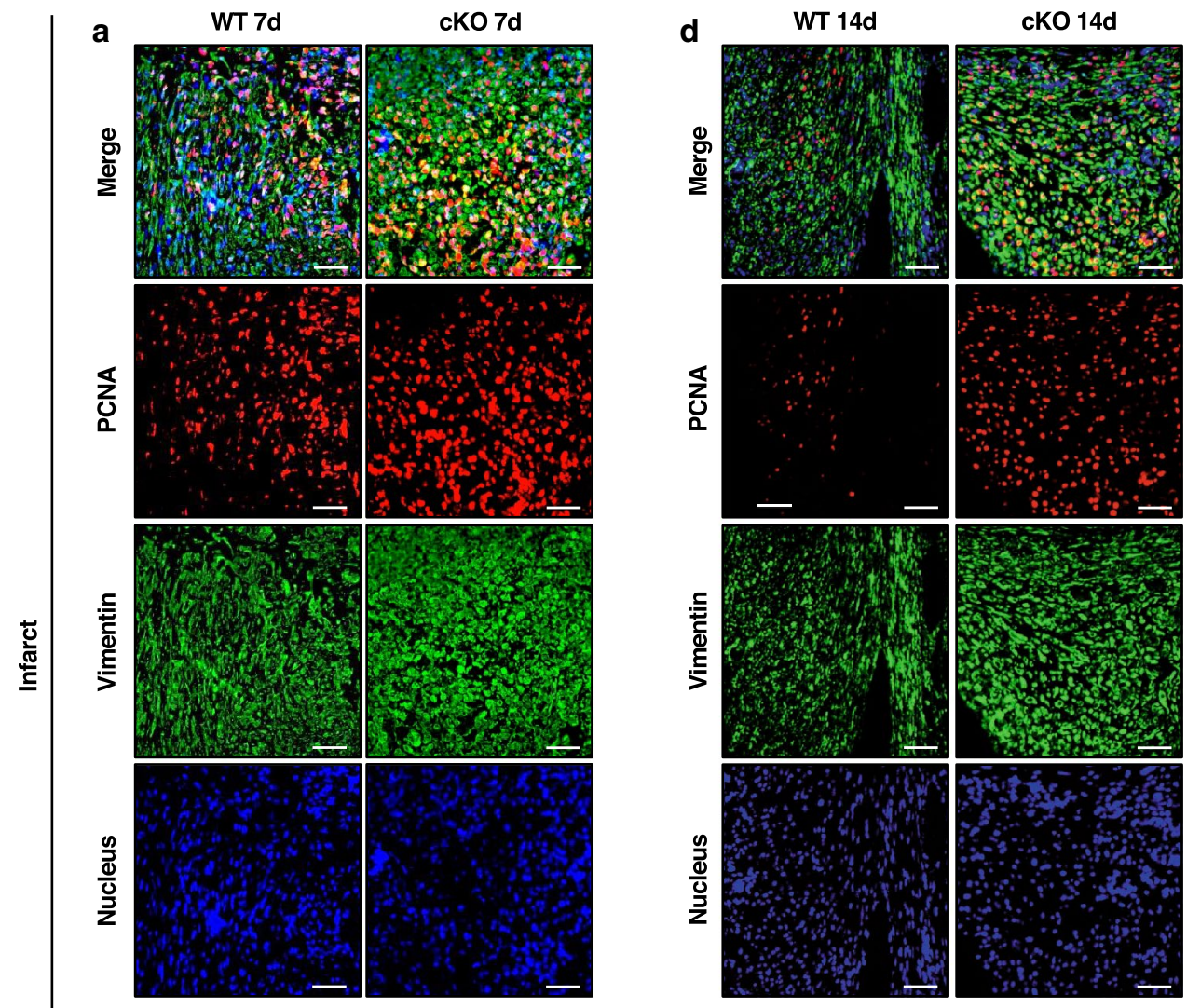

b

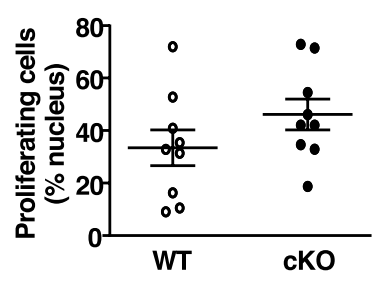

C

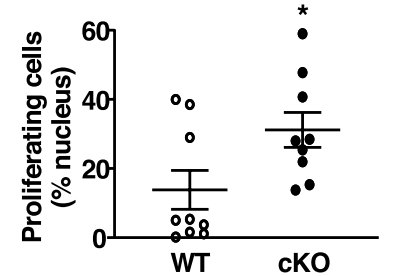

e

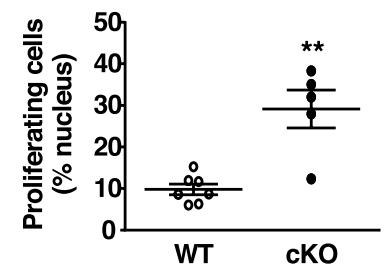

f
힘 
a

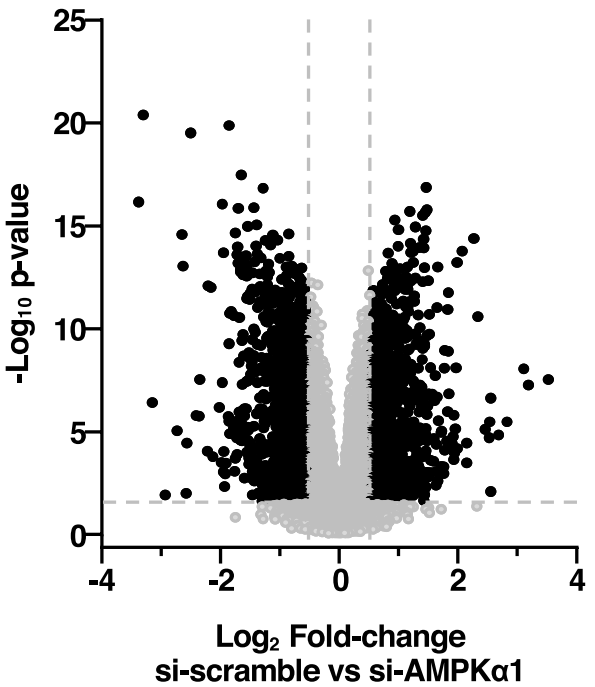

b

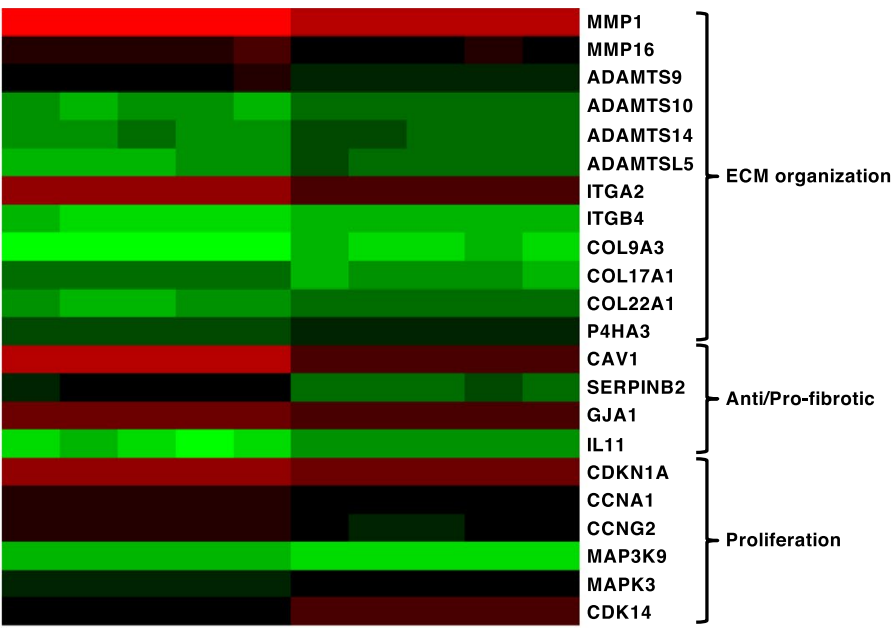

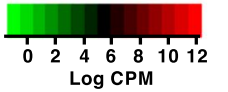

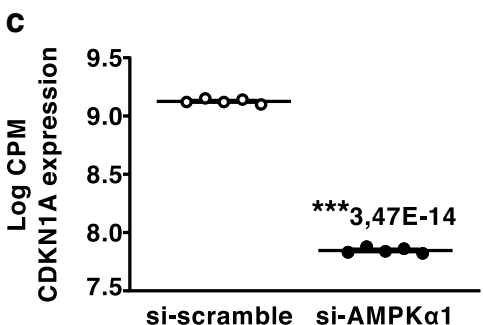

f
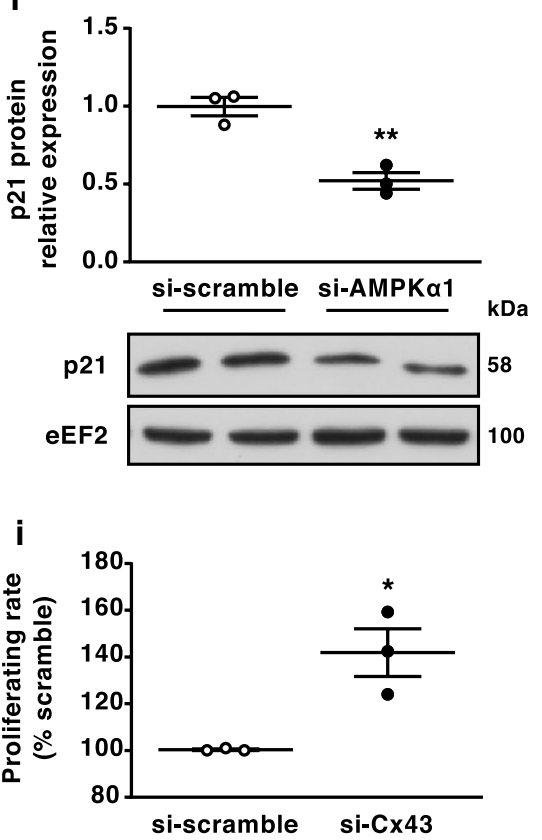

d

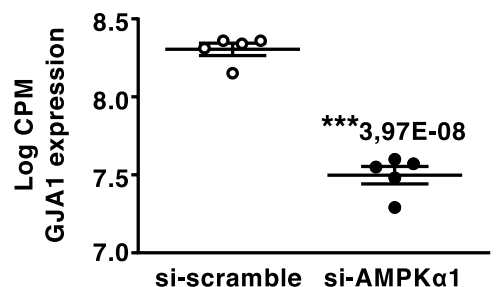

g
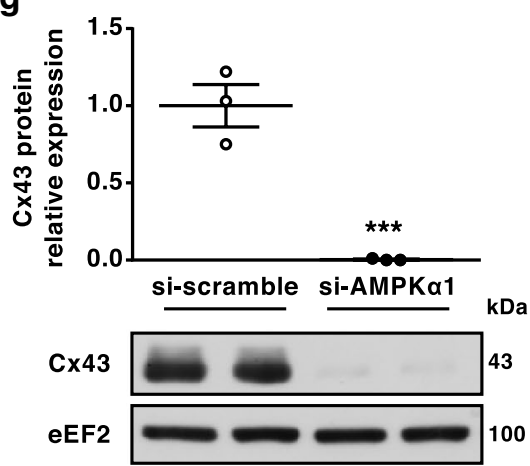

j

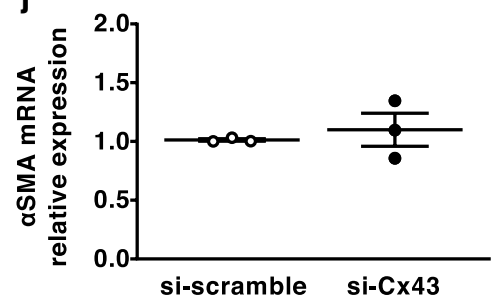

e

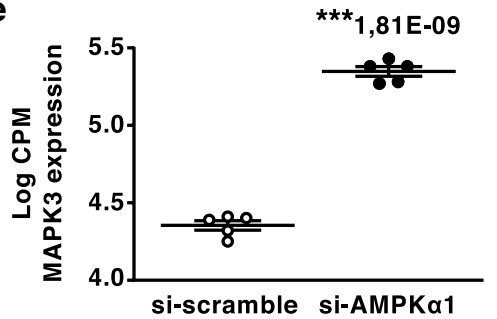

h
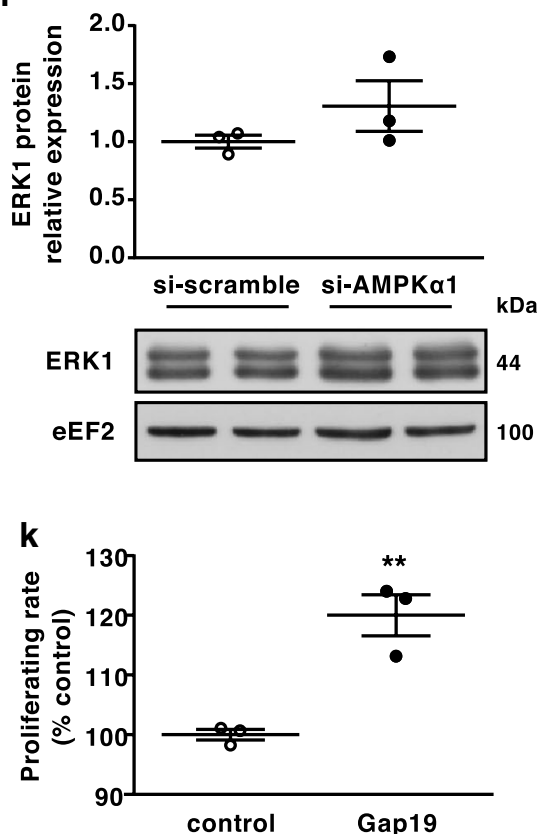
4Fig. 5 AMPK $\alpha 1$ regulates Cx43 expression in CFs. a-h Human cardiac fibroblasts (HCFs) were transfected with AMPK $\alpha 1$-targeting siRNA or scramble for $48 \mathrm{~h}$ and differential genes expression was analysed by RNA-Seq ( $n=5$ biological replicates/group) (a-e) or protein expression was assessed by Western blotting $(n=3$ biological replicates/group) (f-h). a Volcano plot representation of differentially expressed genes. b Heat map representation of differentially expressed genes relevant for fibrosis and CF activity modulation. $\mathbf{c}-\mathbf{h}$ Expression of mRNA (c-e) and corresponding proteins (f-h) relevant for $\mathrm{CFs}$ proliferation modulation. $\mathbf{i}-\mathbf{j}$ HCFs were transfected with $\mathrm{Cx} 43$-targeting siRNA or scramble for $48 \mathrm{~h}$ and proliferation was assessed by flow cytometry measurement of EdU incorporation $(n=3$ biological replicates/group) (i) or $\alpha$ SMA expression wad assessed by RT-qPCR ( $n=3$ biological replicates/group) (j). k HCFs were treated with Gap19 $100 \mu \mathrm{M}$ for $48 \mathrm{~h}$ and proliferation was assessed by flow cytometry measurement of EdU incorporation ( $n=3$ biological replicates/group). Dot plots represent data from biological replicates as well as mean \pm SEM. Statistical significance was determined using false discovery rate (FDR) calculation $(\mathbf{a}-\mathbf{e})$, unpaired $t$ test $(\mathbf{f}, \mathbf{h}, \mathbf{i}$, k) or Mann-Whitney test $(\mathbf{g}, \mathbf{j}) . * p<0.05, * * p<0.01, * * * p<0.001$ compared to corresponding si-scramble or control

\section{AMPKa1 regulates $C x 43$ expression in infarcted areas and isolated fibroblasts of MF-specific AMPKa1 KO mice}

To determine in vivo the impact of the MF-specific AMPK $\alpha 1$ deletion on $\mathrm{Cx} 43$ and miR-125b-5p, their expression was first measured by qRT-PCR in total extracts from infarcted and remote areas of WT and cKO hearts. In the cKO infarcts, Cx43 mRNA expression was 50\% lower at day 7 post-MI, as compared to infarcts of WT littermates (Fig. 7a). In contrast, no genotype-related differences were noted in the remote zone, suggesting that non-fibroblastic cells of either genotype express unaltered $\mathrm{Cx} 43$ levels (Fig. 7b). Expression level of miR-125b-5p in the infarcted or remote areas was not affected at this time point (Fig. 7c, d). We then evaluated $\mathrm{Cx} 43$ and miR125b-5p expression in MFs isolated from WT and cKO infarcted hearts, at 3 days post-MI. In agreement with the in vitro results, Cx43 mRNA expression was robustly reduced in MFs isolated from cKO infarcted hearts (Fig. 7e) and was inversely correlated with the level of miR-125b-5p expression (Fig. 7f). However, miR-125b-5p expression was not significantly different in MFs isolated from $\mathrm{cKO}$ and WT hearts (Fig. 7g), suggesting a likely fine-tuning relationship between miR-125b-5p and Cx43. Finally, $\mathrm{Cx} 43$ protein expression was measured at 14 days postMI (Fig. 7h, i), and we confirmed that it was robustly reduced in cKO, as compared to WT MFs (Fig. 7h), while it remained comparable in WT and cKO isolated cardiomyocytes (Fig. 7i).

\section{Discussion}

In this study, we highlight the crucial role of MF-AMPK $\alpha 1$ in controlling MF properties, scar formation, and LV remodelling post-MI. Mice with MF-specific deletion of
AMPK $\alpha 1$ develop a more tightly-packed collagen scar after MI with a hyperproliferative fibroblast response, and suffer from adverse LV remodelling and functional impairment in the first months after MI. We provide evidence that $\mathrm{Cx} 43$ is downregulated in MFs isolated from the acutely injured myocardium, probably contributing to the pro-fibrotic responses. Mechanistically, we show that AMPK $\alpha 1$ mainly influences $\mathrm{Cx} 43$ expression by a transcriptional mechanism. We also identified a microRNA, miR-125b-5p, which can play a fine-tuning role to silence Cx43 and serve as a positive regulator in the fibrotic remodelling process [47].

Our previous observations had revealed that systemic AMPK $\alpha 1$ invalidation enhanced adverse LV remodelling by increasing fibroblast proliferation, while myodifferentiation and scar maturation were impaired [49]. We thus hypothesised that fibroblastic AMPK $\alpha 1$ was a key signalling element in regulating fibrosis in the infarcted myocardium and an attractive target for therapeutic intervention. Here, we employed a mouse model in which Cre-recombinase is driven by a mouse Postn promoter for selective AMPK $\alpha 1$ deletion in MFs. Indeed, Postn is a recognised MF marker, and is activated in CF in response to numerous cardiac stimuli invoking a fibrotic response, including necrosis $[19,31]$. Three studies have previously investigated the role of MFs in MI-induced fibrotic remodelling using the Postn-Cre model. Specific MFinvalidation of glycogen synthase kinase $3 \beta$ (GSK-3 $\beta$ ) was associated with hyperactivation of canonical TGF- $\beta$ signalling, resulting in excessive fibrosis and LV dilatation in a mouse MI model [37]. In contrast, MF-specific downregulation of Sox 9 reduced ECM deposition in infarcted hearts [60]. Finally, Kong et al. recently reported that cellspecific activation of Smad3 signalling in cardiomyocytes and CFs differentially regulates repair and remodelling of the infarcted heart [35]. Using R26-stop ${ }^{\mathrm{f} / \mathrm{fl}}$-EYFP reporter animals, we clearly demonstrated that Cre-recombinase is selectively expressed in interstitial cells of infarcted areas, validating the use of Postn-Cre model. AMPK $\alpha 1$-specific deletion in MFs is associated with stimulating proliferation post-MI. MF hyperactivity leads to excessive fibrosis that aggravates MI-induced LV dilatation. cKO mice subjected to MI are characterised by increased collagen deposition and density in infarct core and border zones, without changes in cardiac LOX expression or fibres cross-linking. These observations contrast with the AMPK $\alpha 1$ systemic KO mouse phenotype, with its markedly reduced myocardial LOX expression, resulting in defective collagen scar maturation [49]. The genotype-related difference could be accounted for by non-CF cardiac cells in our current study, which still express AMPK $\alpha 1$, maintain LOX expression, and thus contribute to collagen maturation, even in the absence of AMPK $\alpha 1$ in MFs. Though AMPK $\alpha 1$ systemic 

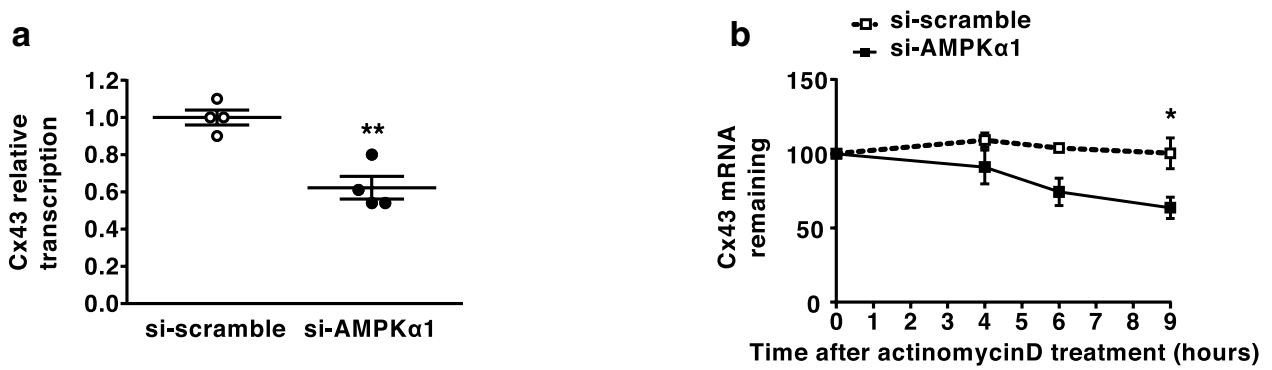

C

\section{5' uuuuuugagcuaaagUCAGGGA 3' Position 769-790 of human GJA1 3'UTR \\ 3' aguguucaaucccagAGUCCCU 5, hsa-miR-125b-5p}
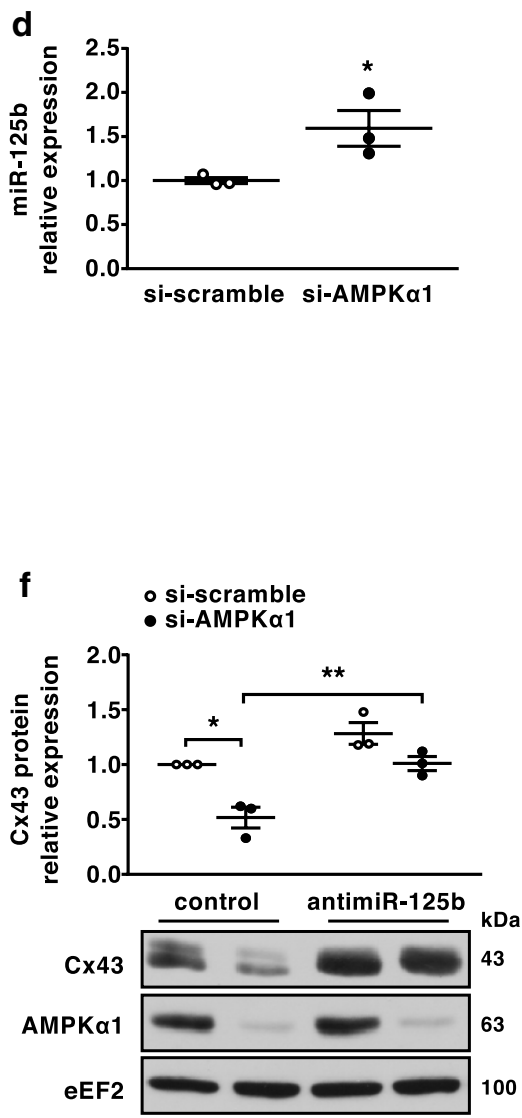

Fig. 6 AMPK $\alpha 1$ regulates $\mathrm{Cx} 43$ transcription and $\mathrm{Cx} 43$ mRNA degradation by a mechanism involving miR-125b-5p. a $\mathrm{Cx} 43$ promotor activity measurement in AMPK $\alpha 1$-deficient or control HEK293 cells. HEK293 cells were co-transfected with a luciferase-reporter plasmid and AMPK $\alpha 1$-targeting siRNA or scramble $(n=4$ biological replicates/group). Results are expressed as luciferase activity relative to scramble. b Human cardiac fibroblasts (HCFs) were transfected with AMPK $\alpha 1$-targeting siRNA or scramble for $48 \mathrm{~h}$ before being treated with actinomycin D $5 \mu \mathrm{g} / \mathrm{mL}$. Cx43 expression was analysed at the different time points by RT-qPCR ( $n=3$ biological replicates/group). Results are expressed as the mean of fold change over corresponding basal state. $\mathbf{c}$ In silico determination of miR-125b-5p predicted target sites in the 3'UTR of Cx43 mRNA by Diana tools, Pictar and microRNA.org. d HCFs were transfected with AMPK $\alpha 1$-targeting siRNA or scramble for $48 \mathrm{~h}$ and miR-125b-5p expression was assessed by
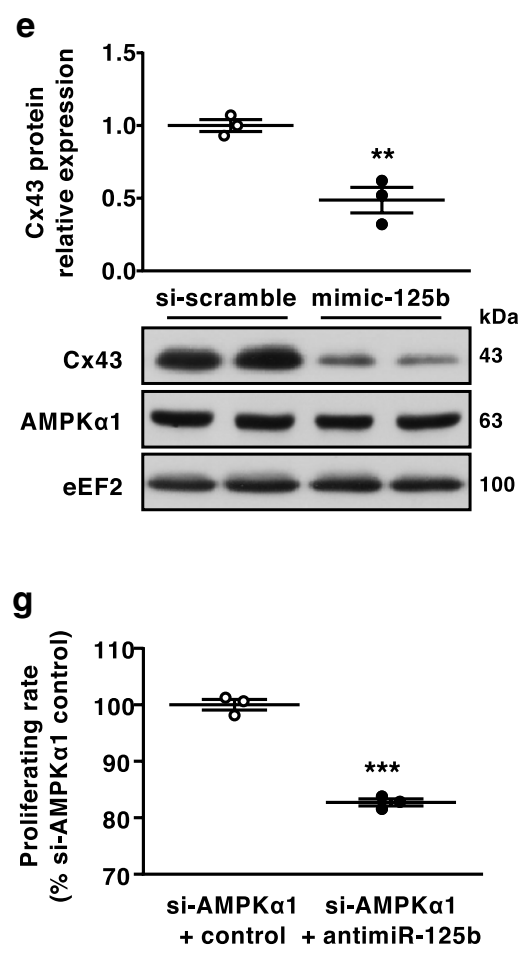

RT-qPCR ( $n=3$ biological replicates/group). Results are expressed as fold change over scramble. e HCFs were transfected with miR125b-5p mimic or control for $48 \mathrm{~h}$, with $\mathrm{Cx} 43$ expression analysed by Western blotting ( $n=3$ biological replicates/group). f HCFs were transfected with AMPK $\alpha 1$-targeting siRNA or scramble along with antagomir-125b-5p or control and $\mathrm{Cx} 43$ expression was evaluated by Western blotting ( $n=3$ biological replicates/group). g HCFs were transfected with AMPK $\alpha 1$-targeting siRNA or scramble along with antagomir-125b-5p or control for $48 \mathrm{~h}$ and proliferation was assessed by flow cytometry measurement of EdU incorporation ( $n=3$ biological replicates/group). Dot-plots represent data from biological replicates as well as mean \pm SEM. Significance was determined by unpaired $t$ test $(\mathbf{a}, \mathbf{d}, \mathbf{e}, \mathbf{g})$ or two-way ANOVA followed by Sidak's multiple comparisons test $(\mathbf{b}, \mathbf{f}) . * p<0.05,{ }^{*} p<0.01, * * * p<0.01$ compared to corresponding si-scramble or control 

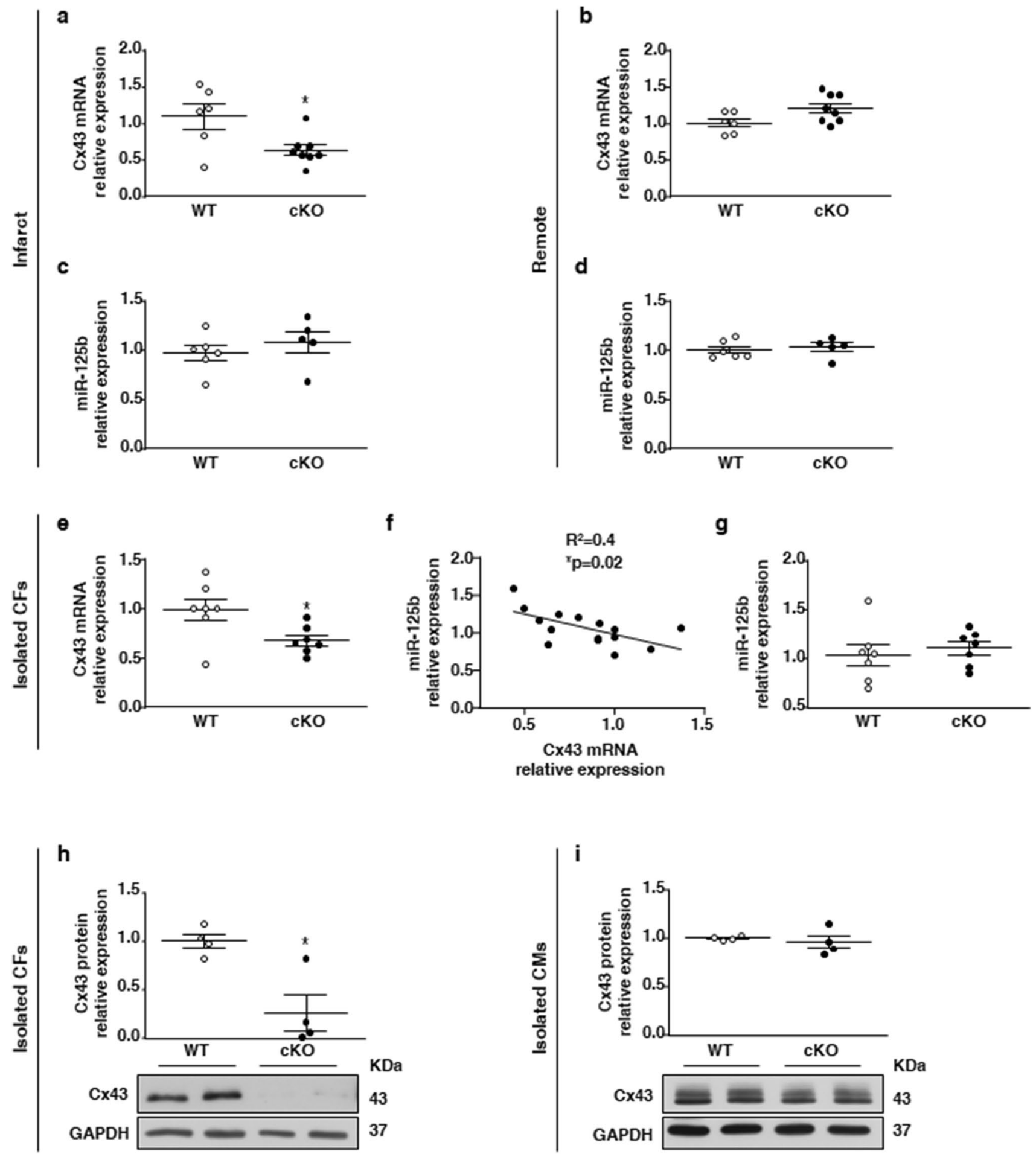

Fig. 7 AMPK $\alpha 1$ regulates $\mathrm{Cx} 43$ expression in infarcted areas and isolated fibroblasts of MF-specific AMPK $\alpha 1$ KO mice. a-d qRT-PCR measurement of Cx43 mRNA (a, b) and miR-125b-5p (c, d) expression in the infarcted $(\mathbf{a}, \mathbf{c})$ and remote $(\mathbf{b}, \mathbf{d})$ myocardium of MF-specific AMPK $\alpha 1 \mathrm{KO}(\mathrm{cKO})$ and littermates WT (WT) mice at 7 days post-myocardial infarction (MI) ( $n=5-8$ mice/group). e, g qRT-PCR measurement of Cx43 mRNA (e) and miR-125b-5p (g) expression in isolated MFs from cKO and WT hearts at 3 days post-MI $(n=7$ mice/group). f Correlation between $\mathrm{Cx} 43$ and miR-125b expressions

in MFs isolated from cKO and WT hearts at 3 days post-MI $(n=14)$. h, i Western blot analysis of Cx43 protein expression in isolated MFs (h) or cardiomyocytes (CMs) (i) from cKO and WT hearts at 14 days post-MI ( $n=4$ mice/group). Dot plots represent data from individual mouse hearts, as well as mean \pm SEM. Statistical significance was determined by unpaired $t$ test $(\mathbf{a}-\mathbf{e}, \mathbf{g}, \mathbf{h})$ or Mann-Whitney test (i) and correlation was assessed using the Pearson coefficient $r$ calculation (f). $* p<0.05$ compared to WT 
KO mice exhibit reduced LOX expression and collagen maturation, MF-specific deletion of AMPK $\alpha 1$ results in enhanced fibrosis and well-aligned and thickly packed collagen fibres, with exacerbated LV dilatation and impaired cardiac function. An over-compliant scar has been well recognised to cause LV dilatation and even cardiac rupture $[49,68,69]$. Inversely, excessive collagen type I deposition or maturation has been reported to increase $\mathrm{LV}$ wall stress, along with exacerbated compensation and LV dilatation $[21,37,66]$. It is, therefore, not surprising that the two genotypes studied (systemic KO and $\mathrm{CKO}$ ) exhibited a deleterious phenotype and exacerbated LV remodelling, albeit via different fibrotic responses.

Interestingly, increased fibrosis in cKO hearts is associated with markedly decreased $\mathrm{Cx} 43$ expression in MFs. Several studies conducted in non-cardiac tissues have associated a reduction in $\mathrm{Cx} 43$ expression with increased collagen deposition [9, 45, 54]. Regarding the heart, Cx43 is highly expressed in cardiomyocytes and CFs [44]. Abnormal cardiac $\mathrm{Cx} 43$ expression has been reported in human ischaemic and dilated cardiomyopathies [16]. Mitochondrial $\mathrm{Cx} 43$ was even demonstrated to play a role in cardiomyocyte ischaemic conditioning by modulating $\mathrm{K}^{+}$influx and ROS production [22]. In addition, partial Cx43 deficiency has been associated with an exaggerated fibrotic response in mice submitted to pressure overload through transverse aortic constriction, or to chronic Angiotensin II treatment [29, 67]. Finally, this inverse relationship between $\mathrm{Cx} 43$ expression and cardiac fibrosis has been recently demonstrated in rats submitted to MI and treated with Dexmedetomidine, an $\alpha 2$-adrenoceptor agonist [71]. Mechanistically, $\mathrm{Cx} 43$ expression levels were shown to be related to CF proliferation $[29,75,76]$. Interestingly, tumour cells exhibit similar effects. Various studies have described that diminished levels of $\mathrm{Cx} 43$ were inversely correlated to tumour proliferation [2, 27, 57, 62]. In line with our findings, $\mathrm{Cx} 43$ expression was shown to be downregulated by miR-125b-5p through its binding with Cx43 mRNA 3' UTR in glioma cells [3, 30]. Together, these studies support an important role for $\mathrm{Cx} 43$ in fibroblast activation and proliferation. At present, the molecular mechanism underlying the increased proliferation remains unknown. Our data with the mimetic peptide Gap19 support a role of $\mathrm{Cx} 43$ hemichannels in the regulation of this process. By facilitating bidirectional passage over the plasma membrane of ions and signalling or metabolic molecules, $\mathrm{Cx} 43$ hemichannels may modulate various biological responses [32]. Of note, previous studies have shown that Cxs fragments can be found within the nucleus and control transcription of genes regulating cell proliferation $[10,36]$. Regarding the link between AMPK and $\mathrm{Cx} 43, \mathrm{Li}$ et al. reported that AMPK activation likely protects cardiac gap junctions from remodelling under hyperglycemia [40]. Our data strongly argue in favour of
AMPK and Cx43 intervening in the fibrotic process. Our hypothesis is that AMPK $\alpha 1$ has not to be overexpressed or activated to regulate MF proliferation and restrain fibrosis, but can exert its function in a basal state, through non-catalytic mechanisms such as scaffolding of protein complexes, protein interactions or subcellular targeting [55]. These noncatalytic functions might explain how AMPK $\alpha 1$ influences $\mathrm{Cx} 43$ expression in MFs, and consequently MF activity, by both a transcriptional and a post-transcriptional mechanism involving miR-125b-5p. The latter was previously shown to be up-regulated in mouse and human fibrotic hearts, while playing a functional role in cardiac fibrogenesis [47]. Several studies have reported on AMPK-dependent microRNA regulation. Recently, the transcriptional regulation of miR-184 by AMPK has been demonstrated in pancreatic islets [42]. In addition, AMPK has proven to indirectly regulate microRNAs by phosphorylating p53 or increasing expression of $\beta$-arrestin, two proteins involved in their post-transcriptional processing $[34,39,70]$. Although our in vitro results clearly show an AMPK-dependent regulation of miR-125b-5p in fibroblasts, future work will aim to confirm that this regulation occurs in vivo and to determine the precise mechanism by which AMPK $\alpha 1$ affects the levels of this microRNA.

Although our study focused on the AMPK $\alpha 1-\mathrm{Cx} 43$ axis, RNA-sequencing analysis carried out on AMPK $\alpha 1$-deficient HCFs highlighted AMPK $\alpha 1$ as a key signalling element regulating a plethora of fibrotic genes. For example, MMP-1, IL-11, or Caveolin-1 are strongly modulated in AMPK $\alpha 1-$ deficient HCFs and considered as key fibrotic factors [43, 59]. Therefore, their possible contribution to the pro-fibrotic phenotype observed in MF-specific AMPK $\alpha 1$ KO mice cannot be excluded.

A limitation of our study is the use of LAD coronary artery permanent ligation model to produce a large scar and severe remodelling, while the ischaemia/reperfusion (I/R) model reflects better the clinical situation observed in human following an acute MI. I/R can confer other advantages and it will be interesting to investigate whether fibroblastic AMPK $\alpha 1$ can also play important roles in this condition where the temporal dynamics of the inflammatory response and the ROS-related oxidative stress might be playing a greater role during the development of cardiac remodelling and heart failure.

In conclusion, our work adds momentum to the emerging notion that dampening MF in a timely fashion, that does not interfere with its role in cardiac repair, may be a new therapeutic strategy in heart failure prevention. Here, we highlight a novel central regulator of $\mathrm{CF}$ activity-AMPK $\alpha 1$ - that might constitute a potential target for pharmacological antifibrotic applications.

Supplementary Information The online version contains supplementary material available at https://doi.org/10.1007/s00395-021-00846-y. 
Acknowledgements The authors would like to thank Patrick Gilon for providing R26-stop ${ }^{\mathrm{f} / \mathrm{fl}}$-EYFP reporter mice; Michèle de Beukelaer for providing support in histology; Paolo Carai for his help in processing cardiac tissue for electron microscopy; Delphine Thibou and Emmanuel Vandenhooft for animal care.

Author contributions CD conducted experiments, acquired data, analysed data, wrote and edited the manuscript. EPD conducted experiments, acquired data, analysed data, wrote and edited the manuscript. DCZ gave conceptual advice related to statistical analysis and edited the manuscript. SJC provided Postn-Cre mice and edited the manuscript. AG conducted experiments and acquired data. $\mathrm{CB}$ provided experimental and conceptual advice on immunohistochemistry experiments. JA, BB and JLG carried out biostatistical and RNA-seq data analyses. SH gave conceptual advice, discussed results and edited the manuscript. APP gave conceptual advice related to electron microscopy and edited the manuscript. SV conducted experiments, acquired data and analysed data. JC conducted experiments and acquired data. JLB discussed results and their implications, provided conceptual advice and edited the manuscript. MV conducted experiments, acquired data, analysed data and edited the manuscript. PS discussed results and their implications, provided conceptual advice and edited the manuscript. SJ discussed results and their implications, provided conceptual advice and edited the manuscript. LB discussed results and their implications and edited the manuscript. CB conceived and designed the study, secured funding, discussed results and their implications and edited the manuscript. SH conceived and designed the study, secured funding, discussed results and their implications, wrote and edited the manuscript. All the authors read and approved the final manuscript before submission.

Funding This work was supported by Grants from Fonds National de la Recherche Scientifique et Médicale (FNRS, Belgium), and Action de Recherche Concertée de la Communauté Wallonie-Bruxelles, Belgium (ARC 13/18-051, ARC 16/21-074), and with unrestricted Grants from Astra Zeneca. CD was supported by a FRIA fellowship (FNRS, Belgium) and by a Bourse du Patrimoine (UCL, Belgium). EPD was supported by a European Society of Cardiology (ESC) Research Grant and by the Fonds de Recherche Clinique (Cliniques Universitaires SaintLuc, Belgium). SJC was supported by National Institutes of Health Grants HL135657 and HL148165. LB and SH work as senior research associates at FNRS, Belgium.

Availability of data and materials Raw and processed RNA-seq data were deposited and made publicly available on the Gene Expression Omnibus (GSE147470).

Code availability Not applicable.

\section{Compliance with ethical standards}

Conflict of interest CB has received Grant support from Astra Zeneca. The remaining authors declare no competing interests.

Ethics approval Animal handling and experimental procedures were approved by the local authorities (Comité d'éthique facultaire pour l'expérimentation animale, 2012/UCL/MD/003 and 2016/UCL/ $\mathrm{MD} / 027$ ) and performed in accordance with the Guide for the Care and Use of Laboratory Animals, published by the US National Institutes of Health (NIH Publication, revised 2011).

Consent to participate Not applicable.

Consent for publication Not applicable.
Open Access This article is licensed under a Creative Commons Attribution 4.0 International License, which permits use, sharing, adaptation, distribution and reproduction in any medium or format, as long as you give appropriate credit to the original author(s) and the source, provide a link to the Creative Commons licence, and indicate if changes were made. The images or other third party material in this article are included in the article's Creative Commons licence, unless indicated otherwise in a credit line to the material. If material is not included in the article's Creative Commons licence and your intended use is not permitted by statutory regulation or exceeds the permitted use, you will need to obtain permission directly from the copyright holder. To view a copy of this licence, visit http://creativecommons.org/licenses/by/4.0/.

\section{References}

1. Alesutan I, Voelk1 J, Stockigt F, Mia S, Feger M, Primessnig U, Sopjani M, Munoz C, Borst O, Gawaz M, Pieske B, Metzler B, Heinzel F, Schrickel JW, Lang F (2015) AMP-activated protein kinase alpha1 regulates cardiac gap junction protein connexin 43 and electrical remodeling following pressure overload. Cell Physiol Biochem 35:406-418. https://doi.org/10.1159/00036 9706

2. Avanzo JL, Mennecier G, Mesnil M, Hernandez-Blazquez FJ, Fukumasu H, da Silva TC, Rao KV, Dagli ML (2007) Deletion of a single allele of $\mathrm{Cx} 43$ is associated with a reduction in the gap junctional intercellular communication and increased cell proliferation of mouse lung pneumocytes type II. Cell Prolif 40:411-421. https://doi.org/10.1111/j.1365-2184.2007.00440.x

3. Calderon JF, Retamal MA (2016) Regulation of connexins expression levels by microRNAs, an update. Front Physiol 7:558. https ://doi.org/10.3389/fphys.2016.00558

4. Cao H, Wang X, Ying S, Huang C (2018) AMPKalpha2 deficiency enhanced susceptibility to ventricular arrhythmias in mice by the role of beta-adrenoceptor signaling. Exp Biol Med (Maywood) 243(8):708-714. https://doi.org/10.1177/1535370218767389

5. Castanares-Zapatero D, Bouleti C, Sommereyns C, Gerber B, Lecut C, Mathivet T, Horckmans M, Communi D, Foretz M, Vanoverschelde JL, Germain S, Bertrand L, Laterre PF, Oury C, Viollet B, Horman S, Beauloye C (2013) Connection between cardiac vascular permeability, myocardial edema, and inflammation during sepsis: role of the alpha1AMP-activated protein kinase isoform. Crit Care Med 41:e411-422. https://doi.org/10.1097/ CCM.0b013e31829866dc

6. Cerqueira MD, Weissman NJ, Dilsizian V, Jacobs AK, Kaul S, Laskey WK, Pennell DJ, Rumberger JA, Ryan T, Verani MS (2002) Standardized myocardial segmentation and nomenclature for tomographic imaging of the heart. A statement for healthcare professionals from the Cardiac Imaging Committee of the Council on Clinical Cardiology of the American Heart Association. Circulation 105:539-542. https://doi.org/10.1161/hc0402.102975

7. Chen F, Zhao WT, Chen FX, Fu GS, Mou Y, Hu SJ (2014) High glucose promotes gap junctional communication in cultured neonatal cardiac fibroblasts via AMPK activation. Mol Biol (Mosk) 48:687-695. https://doi.org/10.1134/S0026893314040025

8. Chen KH, Hsu HH, Lee CC, Yen TH, Ko YC, Yang CW, Hung CC (2014) The AMPK agonist AICAR inhibits TGF-beta1 induced activation of kidney myofibroblasts. PLoS ONE 9:e106554. https ://doi.org/10.1371/journal.pone.0106554

9. Cogliati B, Vinken M, Silva TC, Araujo CM, Aloia TP, Chaible LM, Mori CM, Dagli ML (2015) Connexin 43 deficiency accelerates skin wound healing and extracellular matrix remodeling in mice. J Dermatol Sci 79:50-56. https://doi.org/10.1016/j.jderm sci.2015.03.019 
10. Dang X, Doble BW, Kardami E (2003) The carboxy-tail of connexin-43 localizes to the nucleus and inhibits cell growth. Mol Cell Biochem 242:35-38. https://doi.org/10.1023/a:1021152709 313

11. Daskalopoulos EP, Dufeys C, Bertrand L, Beauloye C, Horman $S$ (2016) AMPK in cardiac fibrosis and repair: actions beyond metabolic regulation. J Mol Cell Cardiol 91:188-200. https://doi. org/10.1016/j.yjmcc.2016.01.001

12. de Meester C, Timmermans AD, Balteau M, Ginion A, Roelants V, Noppe G, Porporato PE, Sonveaux P, Viollet B, Sakamoto K, Feron O, Horman S, Vanoverschelde JL, Beauloye C, Bertrand L (2014) Role of AMP-activated protein kinase in regulating hypoxic survival and proliferation of mesenchymal stem cells. Cardiovasc Res 101:20-29. https://doi.org/10.1093/cvr/cvt227

13. Du J, Guan T, Zhang H, Xia Y, Liu F, Zhang Y (2008) Inhibitory crosstalk between ERK and AMPK in the growth and proliferation of cardiac fibroblasts. Biochem Biophys Res Commun 368:402-407. https://doi.org/10.1016/j.bbrc.2008.01.099

14. Ewels P, Magnusson M, Lundin S, Kaller M (2016) MultiQC: summarize analysis results for multiple tools and samples in a single report. Bioinformatics 32:3047-3048. https://doi.org/10.1093/ bioinformatics/btw354

15. Fontes MS, Raaijmakers AJ, van Doorn T, Kok B, Nieuwenhuis $S$, van der Nagel R, Vos MA, de Boer TP, van Rijen HV, Bierhuizen MF (2014) Changes in $\mathrm{Cx} 43$ and NaV15 expression precede the occurrence of substantial fibrosis in calcineurin-induced murine cardiac hypertrophy. PLoS ONE 9:e87226. https://doi. org/10.1371/journal.pone.0087226

16. Fontes MS, van Veen TA, de Bakker JM, van Rijen HV (2012) Functional consequences of abnormal $\mathrm{Cx} 43$ expression in the heart. Biochim Biophys Acta 1818:2020-2029. https://doi. org/10.1016/j.bbamem.2011.07.039

17. Frangogiannis NG (2018) Cardiac fibrosis: cell biological mechanisms, molecular pathways and therapeutic opportunities. Mol Aspects Med 65:70-99. https://doi.org/10.1016/j. mam.2018.07.001

18. Frangogiannis NG (2015) Pathophysiology of myocardial infarction. comprehensive. Physiology 5:1841-1875. https://doi. org/10.1002/cphy.c150006

19. Fu X, Khalil H, Kanisicak O, Boyer JG, Vagnozzi RJ, Maliken BD, Sargent MA, Prasad V, Valiente-Alandi I, Blaxall BC, Molkentin JD (2018) Specialized fibroblast differentiated states underlie scar formation in the infarcted mouse heart. J Clin Investig 128:2127-2143. https://doi.org/10.1172/JCI98215

20. Gelinas R, Mailleux F, Dontaine J, Bultot L, Demeulder B, Ginion A, Daskalopoulos EP, Esfahani H, Dubois-Deruy E, Lauzier B, Gauthier C, Olson AK, Bouchard B, Des Rosiers C, Viollet B, Sakamoto K, Balligand JL, Vanoverschelde JL, Beauloye C, Horman S, Bertrand L (2018) AMPK activation counteracts cardiac hypertrophy by reducing O-GlcNAcylation. Nat Commun 9:374. https://doi.org/10.1038/s41467-017-02795-4

21. Gonzalez-Santamaria J, Villalba M, Busnadiego O, LopezOlaneta MM, Sandoval P, Snabel J, Lopez-Cabrera M, Erler JT, Hanemaaijer R, Lara-Pezzi E, Rodriguez-Pascual F (2016) Matrix cross-linking lysyl oxidases are induced in response to myocardial infarction and promote cardiac dysfunction. Cardiovasc Res 109:67-78. https://doi.org/10.1093/cvr/cvv214

22. Heusch G (2020) Myocardial ischaemia-reperfusion injury and cardioprotection in perspective. Nat Rev Cardiol 17:773-789. https://doi.org/10.1038/s41569-020-0403-y

23. Heusch G, Gersh BJ (2017) The pathophysiology of acute myocardial infarction and strategies of protection beyond reperfusion: a continual challenge. Eur Heart J 38:774-784. https://doi. org/10.1093/eurheartj/ehw224
24. Heusch G, Libby P, Gersh B, Yellon D, Bohm M, Lopaschuk G, Opie L (2014) Cardiovascular remodelling in coronary artery disease and heart failure. Lancet 383:1933-1943. https://doi. org/10.1016/S0140-6736(14)60107-0

25. Horman S, Morel N, Vertommen D, Hussain N, Neumann D, Beauloye C, El Najjar N, Forcet C, Viollet B, Walsh MP, Hue L, Rider MH (2008) AMP-activated protein kinase phosphorylates and desensitizes smooth muscle myosin light chain kinase. J Biol Chem 283:18505-18512. https://doi.org/10.1074/jbc.M8020 53200

26. Humeres C, Frangogiannis NG (2019) Fibroblasts in the infarcted, remodeling, and failing heart. JACC Basic Transl Sci 4:449-467. https://doi.org/10.1016/j.jacbts.2019.02.006

27. Ionta M, Ferreira RA, Pfister SC, Machado-Santelli GM (2009) Exogenous $\mathrm{Cx} 43$ expression decrease cell proliferation rate in rat hepatocarcinoma cells independently of functional gap junction. Cancer Cell Int 9:22. https://doi.org/10.1186/1475-2867-9-22

28. Iyyathurai J, Wang N, D'Hondt C, Jiang JX, Leybaert L, Bultynck $\mathrm{G}$ (2018) The SH3-binding domain of Cx43 participates in loop/ tail interactions critical for $\mathrm{Cx} 43$-hemichannel activity. Cell Mol Life Sci CMLS 75:2059-2073. https://doi.org/10.1007/s0001 8-017-2722-7

29. Jansen JA, van Veen TA, de Jong S, van der Nagel R, van Stuijvenberg L, Driessen H, Labzowski R, Oefner CM, Bosch AA, Nguyen TQ, Goldschmeding R, Vos MA, de Bakker JM, van Rijen HV (2012) Reduced Cx43 expression triggers increased fibrosis due to enhanced fibroblast activity. Circ Arrhythm Electrophysiol 5:380-390. https://doi.org/10.1161/circep.111.966580

30. Jin Z, Xu S, Yu H, Yang B, Zhao H, Zhao G (2013) miR-125b inhibits connexion 43 and promotes glioma growth. Cell Mol Neurobiol 33:1143-1148. https://doi.org/10.1007/s10571-013-9980-1

31. Kanisicak O, Khalil H, Ivey MJ, Karch J, Maliken BD, Correll RN, Brody MJ, SC JL, Aronow BJ, Tallquist MD, Molkentin JD, (2016) Genetic lineage tracing defines myofibroblast origin and function in the injured heart. Nat Commun 7:12260. https://doi. org/10.1038/ncomms 12260

32. Kar R, Batra N, Riquelme MA, Jiang JX (2012) Biological role of connexin intercellular channels and hemichannels. Arch Biochem Biophys 524:2-15. https://doi.org/10.1016/j.abb.2012.03.008

33. Khalil H, Kanisicak O, Prasad V, Correll RN, Fu X, Schips T, Vagnozzi RJ, Liu R, Huynh T, Lee SJ, Karch J, Molkentin JD (2017) Fibroblast-specific TGF-beta-Smad2/3 signaling underlies cardiac fibrosis. J Clin Investig 127:3770-3783. https://doi. org/10.1172/JCI94753

34. Kohlstedt K, Trouvain C, Boettger T, Shi L, Fisslthaler B, Fleming I (2013) AMP-activated protein kinase regulates endothelial cell angiotensin-converting enzyme expression via p53 and the post-transcriptional regulation of microRNA-143/145. Circ Res 112:1150-1158. https://doi.org/10.1161/CIRCRESAHA .113 .301282

35. Kong P, Shinde AV, Su Y, Russo I, Chen B, Saxena A, Conway SJ, Graff JM, Frangogiannis NG (2018) Opposing actions of fibroblast and cardiomyocyte Smad3 signaling in the infarcted myocardium. Circulation 137:707-724. https://doi.org/10.1161/ CIRCULATIONAHA.117.029622

36. Kotini M, Barriga EH, Leslie J, Gentzel M, Rauschenberger V, Schambony A, Mayor R (2018) Gap junction protein connexin-43 is a direct transcriptional regulator of $\mathrm{N}$-cadherin in vivo. Nat Commun 9:3846. https://doi.org/10.1038/s41467-018-06368-x

37. Lal H, Ahmad F, Zhou J, Yu JE, Vagnozzi RJ, Guo Y, Yu D, Tsai EJ, Woodgett J, Gao E, Force T (2014) Cardiac fibroblast glycogen synthase kinase-3beta regulates ventricular remodeling and dysfunction in ischemic heart. Circulation 130:419-430. https:// doi.org/10.1161/circulationaha.113.008364 
38. Lepropre S, Kautbally S, Octave M, Ginion A, Onselaer MB, Steinberg GR, Kemp BE, Hego A, Wera O, Brouns S, Swieringa F, Giera M, Darley-Usmar VM, Ambroise J, Guigas B, Heemskerk J, Bertrand L, Oury C, Beauloye C, Horman S (2018) AMPK-ACC signaling modulates platelet phospholipids content and potentiates platelet function and thrombus formation. Blood 132(11):1180-1192. https://doi.org/10.1182/blood-2018-02831503

39. Li J, Philip JL, Xu X, Theccanat T, Abdur Razzaque M, Akhter SA (2014) beta-Arrestins regulate human cardiac fibroblast transformation and collagen synthesis in adverse ventricular remodeling. J Mol Cell Cardiol 76:73-83. https://doi.org/10.1016/j.yjmcc .2014.08.006

40. Li X, Yu L, Gao J, Bi X, Zhang J, Xu S, Wang M, Chen M, Qiu F, Fu G (2018) Apelin ameliorates high glucose-induced downregulation of connexin 43 via AMPK-dependent pathway in neonatal rat cardiomyocytes. Aging Dis 9:66-76. https://doi.org/10.14336 /AD.2017.0426

41. Mahoney VM, Mezzano V, Mirams GR, Maass K, Li Z, Cerrone M, Vasquez C, Bapat A, Delmar M, Morley GE (2016) Connexin 43 contributes to electrotonic conduction across scar tissue in the intact heart. Sci Rep 6:26744. https://doi.org/10.1038/srep26744

42. Martinez-Sanchez A, Nguyen-Tu MS, Cebola I, Yavari A, Marchetti P, Piemonti L, de Koning E, Shapiro AMJ, Johnson P, Sakamoto K, Smith DM, Leclerc I, Ashrafian H, Ferrer J, Rutter GA (2018) MiR-184 expression is regulated by AMPK in pancreatic islets. FASEB J 32:2587-2600. https://doi.org/10.1096/ fj.201701100R

43. Mendoza-Topaz C, Nelson G, Howard G, Hafner S, Rademacher P, Frick M, Nichols BJ (2018) Cells respond to deletion of CAV1 by increasing synthesis of extracellular matrix. PLoS ONE 13:e0205306. https://doi.org/10.1371/journal.pone.02053 06

44. Mollenhauer M, Friedrichs K, Lange M, Gesenberg J, Remane L, Kerkenpass C, Krause J, Schneider J, Ravekes T, Maass M, Halbach M, Peinkofer G, Saric T, Mehrkens D, Adam M, Deuschl FG, Lau D, Geertz B, Manchanda K, Eschenhagen T, Kubala L, Rudolph TK, Wu Y, Tang WHW, Hazen SL, Baldus S, Klinke A, Rudolph V (2017) Myeloperoxidase mediates postischemic arrhythmogenic ventricular remodeling. Circ Res 121:56-70. https ://doi.org/10.1161/CIRCRESAHA.117.310870

45. Montgomery J, Ghatnekar GS, Grek CL, Moyer KE, Gourdie RG (2018) Connexin 43-based therapeutics for dermal wound healing. Int J Mol Sci 19(6):1778. https://doi.org/10.3390/ijms19061778

46. Moore-Morris T, Cattaneo P, Guimaraes-Camboa N, Bogomolovas J, Cedenilla M, Banerjee I, Ricote M, Kisseleva T, Zhang L, Gu Y, Dalton ND, Peterson KL, Chen J, Puceat M, Evans SM (2018) Infarct fibroblasts do not derive from bone marrow lineages. Circ Res 122:583-590. https://doi.org/10.1161/CIRCR ESAHA.117.311490

47. Nagpal V, Rai R, Place AT, Murphy SB, Verma SK, Ghosh AK, Vaughan DE (2016) MiR-125b is critical for fibroblast-to-myofibroblast transition and cardiac fibrosis. Circulation 133:291-301. https://doi.org/10.1161/CIRCULATIONAHA.115.018174

48. Nattel S, Burstein B, Dobrev D (2008) Atrial remodeling and atrial fibrillation: mechanisms and implications. Circ Arrhythm Electrophysiol 1:62-73. https://doi.org/10.1161/CIRCEP.107.754564

49. Noppe G, Dufeys C, Buchlin P, Marquet N, Castanares-Zapatero D, Balteau M, Hermida N, Bouzin C, Esfahani H, Viollet B, Bertrand L, Balligand JL, Vanoverschelde JL, Beauloye C, Horman S (2014) Reduced scar maturation and contractility lead to exaggerated left ventricular dilation after myocardial infarction in mice lacking AMPKalpha1. J Mol Cell Cardiol 74:32-43. https://doi. org/10.1016/j.yjmcc.2014.04.018

50. Onselaer MB, Oury C, Hunter RW, Eeckhoudt S, Barile N, Lecut C, Morel N, Viollet B, Jacquet LM, Bertrand L, Sakamoto K,
Vanoverschelde JL, Beauloye C, Horman S (2014) The Ca(2+)/ calmodulin-dependent kinase kinase beta-AMP-activated protein kinase-alpha1 pathway regulates phosphorylation of cytoskeletal targets in thrombin-stimulated human platelets. J Thromb Haemost 12:973-986. https://doi.org/10.1111/jth.12568

51. Orjuela S, Huang R, Hembach KM, Robinson MD, Soneson C (2019) ARMOR: an Automated Reproducible MOdular workflow for preprocessing and differential analysis of RNA-seq data. G3 (Bethesda) 9:2089-2096. https://doi.org/10.1534/g3.119.400185

52. Ozcan C, Battaglia E, Young R, Suzuki G (2015) LKB1 knockout mouse develops spontaneous atrial fibrillation and provides mechanistic insights into human disease process. J Am Heart Assoc 4:e001733. https://doi.org/10.1161/jaha.114.001733

53. Patro R, Duggal G, Love MI, Irizarry RA, Kingsford C (2017) Salmon provides fast and bias-aware quantification of transcript expression. Nat Methods 14:417-419. https://doi.org/10.1038/ nmeth.4197

54. Qiu C, Coutinho P, Frank S, Franke S, Law LY, Martin P, Green CR, Becker DL (2003) Targeting connexin43 expression accelerates the rate of wound repair. Curr Biol CB 13:1697-1703. https ://doi.org/10.1016/j.cub.2003.09.007

55. Rauch J, Volinsky N, Romano D, Kolch W (2011) The secret life of kinases: functions beyond catalysis. Cell Commun Signal CCS 9:23. https://doi.org/10.1186/1478-811X-9-23

56. Robinson MD, McCarthy DJ, Smyth GK (2010) edgeR: a bioconductor package for differential expression analysis of digital gene expression data. Bioinformatics 26:139-140. https://doi. org/10.1093/bioinformatics/btp616

57. Roger C, Mograbi B, Chevallier D, Michiels JF, Tanaka H, Segretain D, Pointis G, Fenichel P (2004) Disrupted traffic of connexin 43 in human testicular seminoma cells: overexpression of Cx43 induces membrane location and cell proliferation decrease. J Pathol 202:241-246. https://doi.org/10.1002/path.1509

58. Rubart M, Tao W, Lu XL, Conway SJ, Reuter SP, Lin SF, Soonpaa MH (2018) Electrical coupling between ventricular myocytes and myofibroblasts in the infarcted mouse heart. Cardiovasc Res 114:389-400. https://doi.org/10.1093/cvr/cvx163

59. Schafer S, Viswanathan S, Widjaja AA, Lim WW, Moreno-Moral A, DeLaughter DM, Ng B, Patone G, Chow K, Khin E, Tan J, Chothani SP, Ye L, Rackham OJL, Ko NSJ, Sahib NE, Pua CJ, Zhen NTG, Xie C, Wang M, Maatz H, Lim S, Saar K, Blachut S, Petretto E, Schmidt S, Putoczki T, Guimaraes-Camboa N, Wakimoto H, van Heesch S, Sigmundsson K, Lim SL, Soon JL, Chao VTT, Chua YL, Tan TE, Evans SM, Loh YJ, Jamal MH, Ong KK, Chua KC, Ong BH, Chakaramakkil MJ, Seidman JG, Seidman CE, Hubner N, Sin KYK, Cook SA (2017) IL-11 is a crucial determinant of cardiovascular fibrosis. Nature 552:110-115. https ://doi.org/10.1038/nature24676

60. Scharf GM, Kilian K, Cordero J, Wang Y, Grund A, Hofmann M, Froese N, Wang X, Kispert A, Kist R, Conway SJ, Geffers R, Wollert KC, Dobreva G, Bauersachs J, Heineke J (2019) Inactivation of Sox 9 in fibroblasts reduces cardiac fibrosis and inflammation. JCI Insight 5(15):e126721. https://doi.org/10.1172/jci.insig ht. 126721

61. Soneson C, Love MI, Robinson MD (2015) Differential analyses for RNA-seq: transcript-level estimates improve gene-level inferences. F1000Res 4:1521. https://doi.org/10.12688/f1000resea rch.7563.2

62. Song M, Yu X, Cui X, Zhu G, Zhao G, Chen J, Huang L (2009) Blockade of connexin 43 hemichannels reduces neointima formation after vascular injury by inhibiting proliferation and phenotypic modulation of smooth muscle cells. Exp Biol Med (Maywood) 234:1192-1200. https://doi.org/10.3181/0902-RM-80

63. Srinivas S, Watanabe T, Lin CS, William CM, Tanabe Y, Jessell TM, Costantini F (2001) Cre reporter strains produced by targeted 
insertion of EYFP and ECFP into the ROSA26 locus. BMC Dev Biol 1:4. https://doi.org/10.1186/1471-213x-1-4

64. Takeda N, Manabe I, Uchino Y, Eguchi K, Matsumoto S, Nishimura S, Shindo T, Sano M, Otsu K, Snider P, Conway SJ, Nagai R (2010) Cardiac fibroblasts are essential for the adaptive response of the murine heart to pressure overload. J Clin Investig 120:254-265. https://doi.org/10.1172/jci40295

65. Tallquist MD, Molkentin JD (2017) Redefining the identity of cardiac fibroblasts. Nat Rev Cardiol 14:484-491. https://doi. org/10.1038/nrcardio.2017.57

66. Valiente-Alandi I, Potter SJ, Salvador AM, Schafer AE, Schips T, Carrillo-Salinas F, Gibson AM, Nieman ML, Perkins C, Sargent MA, Huo J, Lorenz JN, DeFalco T, Molkentin JD, Alcaide P, Blaxall BC (2018) Inhibiting fibronectin attenuates fibrosis and improves cardiac function in a model of heart failure. Circulation 138:1236-1252. https://doi.org/10.1161/CIRCULATIO NAHA.118.034609

67. Valls-Lacalle L, Negre-Pujol C, Rodriguez C, Varona S, ValeraCanellas A, Consegal M, Martinez-Gonzalez J, RodriguezSinovas A (2019) Opposite effects of moderate and extreme Cx43 deficiency in conditional Cx43-deficient mice on angiotensin II-induced cardiac fibrosis. Cells 8(10):1299. https://doi. org/10.3390/cells8101299

68. Van Aelst LN, Voss S, Carai P, Van Leeuwen R, Vanhoutte D, Sanders-van Wijk S, Eurlings L, Swinnen M, Verheyen FK, Verbeken E, Nef H, Troidl C, Cook SA, Brunner-La Rocca HP, Mollmann H, Papageorgiou AP, Heymans S (2015) Osteoglycin prevents cardiac dilatation and dysfunction after myocardial infarction through infarct collagen strengthening. Circ Res 116:425-436. https://doi.org/10.1161/circresaha.116.304599

69. Voorhees AP, DeLeon-Pennell KY, Ma Y, Halade GV, Yabluchanskiy A, Iyer RP, Flynn E, Cates CA, Lindsey ML, Han HC (2015) Building a better infarct: modulation of collagen cross-linking to increase infarct stiffness and reduce left ventricular dilation postmyocardial infarction. J Mol Cell Cardiol 85:229-239. https://doi. org/10.1016/j.yjmcc.2015.06.006
70. Wang J, Song Y, Li H, Shen Q, Shen J, An X, Wu J, Zhang J, Wu Y, Xiao H, Zhang Y (2016) Exacerbated cardiac fibrosis induced by beta-adrenergic activation in old mice due to decreased AMPK activity. Clin Exp Pharmacol Physiol 43:1029-1037. https://doi. org/10.1111/1440-1681.12622

71. Wu SJ, Lin ZH, Lin YZ, Rao ZH, Lin JF, Wu LP, Li L (2020) Dexmedetomidine exerted anti-arrhythmic effects in rat with ischemic cardiomyopathy via upregulation of connexin 43 and reduction of fibrosis and inflammation. Front Physiol 11:33. https ://doi.org/10.3389/fphys.2020.00033

72. Xu H, Zhou Y, Coughlan KA, Ding Y, Wang S, Wu Y, Song P, Zou MH (2015) AMPKalphal deficiency promotes cellular proliferation and DNA damage via p21 reduction in mouse embryonic fibroblasts. Biochim Biophys Acta 1853:65-73. https://doi. org/10.1016/j.bbamcr.2014.10.002

73. Zarrinpashneh E, Beauloye C, Ginion A, Pouleur AC, Havaux X, Hue L, Viollet B, Vanoverschelde JL, Bertrand L (2008) AMPKalpha 2 counteracts the development of cardiac hypertrophy induced by isoproterenol. Biochem Biophys Res Commun 376:677-681. https://doi.org/10.1016/j.bbrc.2008.09.057

74. Zhang P, Hu X, Xu X, Fassett J, Zhu G, Viollet B, Xu W, Wiczer B, Bernlohr DA, Bache RJ, Chen Y (2008) AMP activated protein kinase-alpha2 deficiency exacerbates pressure-overload-induced left ventricular hypertrophy and dysfunction in mice. Hypertension 52:918-924. https://doi.org/10.1161/HYPERTENSIONAHA .108 .114702

75. Zhang Y, Kanter EM, Laing JG, Aprhys C, Johns DC, Kardami E, Yamada KA (2008) Connexin 43 expression levels influence intercellular coupling and cell proliferation of native murine cardiac fibroblasts. Cell Commun Adhes 15:289-303. https://doi. org/10.1080/15419060802198736

76. Zhang Y, Wang H, Kovacs A, Kanter EM, Yamada KA (2010) Reduced expression of $\mathrm{Cx} 43$ attenuates ventricular remodeling after myocardial infarction via impaired TGF-beta signaling. Am J Physiol Heart Circ Physiol 298:H477-487. https://doi. org/10.1152/ajpheart.00806.2009 